CÁCeres-González, Emiro, "Prisión perpetua en Colombia. Análisis de las iniciativas legislativas para su autorización, y de los argumentos «racionales» para su incorporación en el ordenamiento colombiano", Nuevo Foro Penal, 93, (2019).

\title{
Prisión perpetua en Colombia. Análisis de las iniciativas legislativas para su autorización, y de los argumentos uracionales" para su incorporación en el ordenamiento colombiano*
}

Perpetual prison in Colombia. Analysis of the Legislative Initiatives for their authorization, and the rational arguments for their incorporation in the Colombian legal system

\author{
Emiro Cáceres-González**
}

Fecha de recepción: 04/06/2019 - Fecha de aceptación: 23/09/2019

DOI: $10.17230 / n f p .15 .93 .4$

\section{Resumen}

En Colombia se han presentado alrededor de dieciséis proyectos de acto legislativo para modificar el artículo 34 de la Constitución, y así suprimir la prohibición de penas perpetuas; el más reciente ha sido el proyecto de Acto Legislativo 001 de 2019, cuyo contenido consagra que la pena, solamente será revisable, pasados treinta años de privación efectiva de la libertad. La publicación pretende rastrear los intentos realizados por el legislador, para incorporar dicha sanción, y revisar los argumentos usados para justificarla. Así mismo,

* $\quad$ El presente artículo es el producto de una estancia de investigación realizada en la universidad EAFIT durante parte del segundo semestre de 2018. Agradezco al profesor Alfonso Cadavid Quintero y a todo el equipo que hace parte del área de Derecho Penal de la Universidad por su recibimiento, y hacerme sentir como un miembro más, durante el tiempo que permanecí en ese claustro universitario.

* Doctorando, Estado de Derecho y Gobernanza Global - Universidad de Salamanca. Magíster en Derecho penal-Universidad de Salamanca. emiro91507358@usal.es-emirocaceres17@gmail.com 
112 Prisión perpetua en Colombia. Análisis de las Iniciativas Legislativas para su autorización, y de los argumentos "racionales» para su incorporación en el ordenamiento colombiano

EMIro Cáceres-González

demostrar la precaria racionalidad incorporada a las exposiciones de motivos, a los debates legislativos en comisión y plenaria, el carente sustento empírico, su débil justificación, y el uso en su remplazo, de un ya común populismo punitivo, con el que se contraviene además de la Constitución, el Reglamento del Congreso y los pronunciamientos de la Corte Constitucional sobre legislación reflexiva.

\section{Abstract}

In Colombia, around sixteen draft legislative act have been submitted to modify article 34 of the Constitution, thus eliminating the prohibition of life sentences; the most recent has been the project of Legislative Act 001 of 2019, whose content enshrined that the penalty, would only be reviewable, after thirty years of effective deprivation of liberty. The publication aims to trace the attempts made by the legislator so far to incorporate this sanction, and review the arguments used to justify it. The aim is to demonstrate the precarious rationality incorporated in the motives expositions, the legislative debates in committee and in the plenary, the lacking empirical sustention, its weak justification, and the use in its replacement, of an already common punitive populism, with which it contravenes besides the Constitution, the Rules of the Congress and the pronouncements of the Constitutional Court on reflective legislation.

\section{Palabras clave}

Prisión perpetua, Prisión Permanente Revisable, Populismo Punitivo, Proyecto de Acto Legislativo, Reglamento del Congreso, Estado de Cosas Inconstitucional, Consejo Superior de Política Criminal.

\section{Keywords}

Perpetual Prison, permanent revisable prison, Punitive Populism, draft legislative act, Congress Regulation, Unconstitutional State of Things, Superior Council of Criminal Policy.

\section{Sumario}

1. Introducción. 2. Intentos legislativos para incorporar la prisión perpetua en Colombia. 2.1. Motivos ofrecidos por el legislador para justificar la introducción de la prisión permanente revisable. 3. La imperiosa necesidad de incorporar criterios de racionalidad al proceso legislativo en materia penal. 3.1. Desconocimiento del mandato interno: La Ley Orgánica del Reglamento del Congreso (LORC). 3.2. Desconocimiento del mandato externo: Las órdenes impartidas al legislador por la Corte Constitucional Colombiana. 3.2.1. El (des)interés del legislador al concepto previo del Comité Técnico Científico del Consejo Superior de Política Criminal. 4. Conclusiones. 5. Bibliografía. 


\section{Introducción}

Consagra el artículo 34 de la Carta Fundamental que, en Colombia se encuentra prohibida la imposición de las penas de destierro, prisión perpetua y confiscación; sin embargo, desde el año 2007 se ha venido gestando en el Congreso de la República, un recurrente malestar por la restricción que les ha sido impuesta por el constituyente primario sobre la no imposición de penas a perpetuidad, por lo que, en sistemáticas oportunidades y de diferente forma, ha intentado eliminar del ordenamiento supremo tan incómoda limitación.

El último intento de reforma ha sido presentado mediante proyecto de Acto Legislativo (PAL) No. 001 de 2019, el cual tiene como pretensión, la modificación del artículo 34 de la Constitución Política Colombiana, con la excusa de que el uso de la pena a perpetuidad -bajo la eufemística modalidad revisable-, sería excepcional; ello a fin de que ciertos delitos reciban un tratamiento diferenciado por su alto nivel de reprochabilidad; así, para intentar justificarlo, ha sugerido la revisión, pasados 30 años de privación efectiva de la libertad. Pero ésta no ha sido la única iniciativa que se ha radicado en este sentido, por ello, en este artículo intentaremos rastrear los antecedentes legislativos presentados para incorporar la figura de la prisión a perpetuidad en Colombia, y revisar los argumentos sostenidos para justificar su necesidad. Ello a fin de demostrar el nulo sustento empírico ofrecido por el legislador, su débil justificación, el desconocimiento de ciertas órdenes acerca del contenido mínimo que deben entrañar las iniciativas legislativas que comprometan la política criminal del Estado, y el uso, en su remplazo, de un recurrente populismo punitivo.

\section{Intentos legislativos para incorporar la prisión perpetua en Colombia}

Al efectuar un proceso de rastreo, o de ingeniería de reversa, ${ }^{1}$ para identificar las iniciativas dirigidas a modificar el artículo 34 del texto constitucional, encontramos que, la primera proposición de acto legislativo que marca el hito² sobre el tema, tuvo cabida

1 El término es acuñado para un asunto diferente por López Medina, Diego Eduardo, El derecho de los jueces: obligatoriedad del precedente constitucional, análisis de sentencias y líneas jurisprudenciales y teoría del derecho judicial, Bogotá, Legis, 2006. En esta obra, el autor alude a este concepto para referirse a las citaciones internas tendientes a restringir la búsqueda de información analogizable por sus hechos al caso que ahora se decide. Cit. p. 171. 
114 Prisión perpetua en Colombia. Análisis de las Iniciativas Legislativas para su autorización, y de los argumentos "racionales» para su incorporación en el ordenamiento colombiano

EMIro Cáceres-González

en el año $2007^{3}$ mediante la presentación del PAL 023 de 2007 (Cámara) , ${ }^{4}$ el que, al momento de la presentación de ponencia para primer debate, fue acumulado al PAL 038 de 2007 (cámara), ${ }^{5}$ que venía respaldado por el Fiscal General de la época. ${ }^{6}$

El trámite surtido a estos proyectos, luego de su publicación -y posterior acumulación-, fue la presentación de ponencia para primer debate en la Comisión Constitucional respectiva, sin que la misma fuera llevada a cabo, por el retiro de su autor en el mes de noviembre. ${ }^{7}$

En octubre de 2008, fue presentado el PAL 163 (Cámara);:8 en esta oportunidad el pre legislador opta por no señalar alternativa alguna de libertad, limitándose a indicar que dicha pena sería posible para ciertos delitos, atendiendo a su especial trascendencia. ${ }^{9}$ Sobre el trámite impartido a esta iniciativa, es probable que, al haber sido

3 En una de las exposiciones de motivos rastreadas, se hace mención al Proyecto de Acto Legislativo número 034 de 2006, sin embargo, pese a nuestros intentos por encontrarlo, la búsqueda fue infructuosa razón por la que tomamos como punto de partida el PAL 023 de 2007.

$4 \quad$ Vid. Gaceta del Congreso No. 339 de 2007.

5 Vid. Gaceta del Congreso No. 355 de 2007. El texto propuesto era el siguiente: Texto Actual del Artículo 34: Se prohíben las penas de destierro y confiscación. No obstante, por sentencia judicial, se declarará extinguido el dominio sobre los bienes adquiridos mediante enriquecimiento ilícito, en perjuicio del Tesoro Público o con grave deterioro de la moral social. Texto adicional propuesto: Procederá hasta la pena de prisión perpetua para los delitos de acceso carnal violento y homicidio doloso cometidos en menores de 14 años.

6 La propuesta legislativa añadía al artículo 34 antes citado lo siguiente: Solo podrá imponer el legislador la pena de prisión perpetua para castigar, en los casos que se definan como graves, la comisión de hechos punibles relacionados con violación sexual de niños seguida de muerte o lesión grave.

La pena de prisión perpetua será revisada de oficio o a petición de parte cuando el condenado haya cumplido 35 años de privación de la libertad por el órgano jurisdiccional que impuso la condena.

Parágrafo. En ningún caso se podrá aplicar la pena de prisión perpetua a personas que, al momento de la comisión del delito, tuvieren menos de dieciocho años de edad o más de setenta, ni se aplicará a las mujeres en estado de gravidez.

Parágrafo transitorio. El Gobierno Nacional dentro de los treinta (30) días siguientes la expedición de este acto legislativo, deberá presentar el proyecto de ley que desarrolle lo dispuesto en el presente acto legislativo, incluyendo entre otros los siguientes temas: creación de un Registro Nacional de Violadores (RNV), en donde se incluyan los datos filiatorios y genéticos de las personas que hayan reincidido en este tipo de delitos, sus apodos, seudónimos, sobrenombres y fotografías de los violadores en lugares públicos y en redes de Internet.

7 Las razones alegadas por los titulares de cada uno de los proyectos, para justificar la necesidad de su introducción en el ordenamiento jurídico colombiano, serán mencionados en el acápite 2.1 de este artículo. Vid. Gaceta del Congreso No. 685 de 2008.

9 La adición propuesta a la norma constitucional fue la siguiente: Procederá hasta la prisión perpetua para los delitos contra la vida y la integridad personal, contra la libertad individual y otras garantías, contra la libertad, integridad y formación sexuales, contra la familia, cometidos contra personas menores de 14 años. 
presentada tan cerca al vencimiento de la legislatura, ésta solamente hubiera alcanzado la presentación de ponencia positiva para primer debate; ${ }^{10}$ allí, al texto propuesto se le adicionó, que su aplicación se ampliara a los sujetos que cometieran tales conductas, no solo contra menores de 14 años, sino también contra menores de edad con discapacidad física o mental. Finalmente, el proyecto no alcanzó siquiera primer debate, siendo archivado al haberse vencido los términos para su discusión. ${ }^{11}$

En el año 2009, se modifica el instrumento constitucional utilizado, remplazándose el PAL por un proyecto de ley (PL), pero manteniendo la pretensión de modificación del ordenamiento superior en lo concerniente a la eliminación de la prohibición de imposición de penas a perpetuidad en Colombia. ${ }^{12}$ El objeto de éste fue convocar a referendo constitucional, para que el pueblo decidiera si estaba de acuerdo o no, con la modificación del artículo 34 de la Carta Fundamental. ${ }^{13}$

Éste ha sido el intento de modificación constitucional que sobre este tópico ha tenido más impulso a día de hoy, puesto que, luego de los debates respectivos en cada Cámara legislativa, alcanzó a ser promulgado como Ley de la República; ${ }^{14}$ no obstante, luego del control de constitucionalidad por parte del tribunal encargado de su estudio, ${ }^{15}$ éste declaró su inexequibilidad por vicios en su procedimiento.

Luego del anterior pronunciamiento, los intentos legislativos para modificar el artículo 34 de la Constitución Política, aparentemente se apaciguaron. Entre el periodo

10 Vid. Gaceta del Congreso No. 741 de 2008.

11 Fuente: https://congresovisible.uniandes.edu.co/proyectos-de-ley/ppor-medio-de-la-cual-se-modifica-elarticulo-34-de-la-constitucion-politica-cadena-perpetua-abusadores-ninos/1559/\#tab=2 (consultado el 20/01/2019).

12 Proyecto de Ley No. 260 de 2009 (Cámara) Por medio del cual se convoca a un referendo constitucional y se somete a consideración del pueblo un proyecto de reforma constitucional.

13 El texto propuesto para la convocatoria de rreferendo fue el siguiente: El Congreso de Colombia DECRETA: Artículo $1^{\circ}$. Convócase (sic) al pueblo colombiano para que en desarrollo de lo previsto por los artículos 374 y 378 de la Constitución Política, mediante Referendo Constitucional decida si aprueba el siguiente: PROYECTO DE ACTO LEGISLATIVO. EI Pueblo de Colombia.

DECRETA:

Artículo $1^{\circ}$. El artículo 34 de la Constitución Nacional quedará así: artículo 34: Se prohíben las penas de destierro, prisión perpetua y confiscación. No obstante, por sentencia judicial, se declarará extinguido el dominio sobre los bienes adquiridos mediante enriquecimiento ilícito, en perjuicio del Tesoro Público o con grave deterioro de la moral social.

Con relación a los delitos de homicidio doloso, violación y explotación sexual, maltrato severo y secuestro cometidos contra menores de 14 años y menores de edad con discapacidad física o mental, procederá la pena de prisión perpetua, de acuerdo con la ley. Vid. Gaceta del Congreso No. 080 de 2009.

14 Ley 1327 de 2009.

15 Corte Constitucional, Sentencia C-397 de 2010. 
116 Prisión perpetua en Colombia. Análisis de las Iniciativas Legislativas para su autorización, y de los argumentos "racionales» para su incorporación en el ordenamiento colombiano

Emiro Cáceres-González

2010-2014, no se radicaron propuestas legislativas en este sentido, siendo a partir del 2015, y como consecuencia de algunos hechos que captaron la atención de los medios de comunicación y el repudio de la comunidad en general, que se presentaran los PAL 204 de 2015 (Cámara), ${ }^{16} 029$ de 2015 (Cámara), ${ }^{17}$ y 211 de 2016. ${ }^{18}$ Del contenido de los tres proyectos -tal como lo apuntaremos más adelante-, la propuesta de articulado -y también curiosamente- su justificación, es prácticamente la misma, pese a provenir de autores y partidos políticos diferentes, ${ }^{19}$ por lo que no deja de ser llamativa, la coincidencia conceptual -prácticamente plagiada-, de los argumentos ofrecidos por los autores de estas iniciativas al momento de realizar su ingente esfuerzo propositivo, dirigido a modificar una norma de tan trascendental raigambre. ${ }^{20}$

Sobre las etapas surtidas en cada proyecto, los dos primeros fueron objeto de presentación de ponencia, ${ }^{21}$ sin conseguir primer debate, siendo su suerte el archivo por vencimiento de términos; el tercer proyecto, solo consiguió publicación, sin recibir siquiera primera ponencia, ordenándose su archivo, por la misma razón que los anteriores. ${ }^{22}$

En la legislatura 2016, el Senado de la República hizo lo propio presentando el PAL 12, que en su exposición de motivos (EM), enaltecía el intento de modificación constitucional realizado en 2009 por la señora Gilma Jiménez (q.e.p.d.), quien para ese año fuera concejal de Bogotá, y posteriormente, con la bandera de la prisión perpetua,

16 Vid. Gaceta del Congreso No. 063 de 2015; ponencia para primer debate Gaceta del Congreso No. 268 de 2015.

17 Vid. Gaceta del Congreso No. 552 de 2015; ponencia para primer debate Gaceta del Congreso No. 635 de 2015.

18 Vid. Gaceta del Congreso No. 1133 de 2016. No alcanzó siquiera, presentación de ponencia para iniciar debate legislativo, pues por lo tardío de su presentación, fue archivado por vencimiento de términos. Fuente: https://congresovisible.uniandes.edu.co/proyectos-de-ley/ppor-medio-del-cualse-modifica-el-articulo-34-de-la-constitucion-politica-suprimiendo-la-prohibicion-de-la-pena-deprision-perpetua-cadena-perpetua/8757/\# tab=2 (consultado el 25/01/2019).

19 El contenido de las exposiciones de motivos se abordará infra.

20 En los tres proyectos de acto legislativo, se presentó inalterable la siguiente redacción de modificación constitucional: Artículo 34. Se prohíben las penas de destierro y confiscación.

No obstante, por sentencia judicial, se declarará extinguido el dominio sobre los bienes adquiridos mediante enriquecimiento ilícito, en perjuicio del Tesoro Público o con grave deterioro de la moral social.

De manera excepcional, se podrá imponer pena de prisión perpetua en los eventos en los que la gravedad del delito lo amerite. En todo caso, la pena será revisable en los términos y condiciones que establezca la ley.

21 Vid. Gaceta del Congreso No. 268 y 635 de 2015, respectivamente.

22 Ver nota 19. 
consiguiera un escaño en el Senado de la República. ${ }^{23}$ El acto legislativo en comento, solamente consiguió su publicación en la Gaceta del Congreso, ${ }^{24}$ sin que sobre él, se surtiera ponencia 0 debate alguno.

Tres fueron los intentos de reforma constitucional que en 2017 se presentaron para introducir la figura de la prisión a perpetuidad; las propuestas fueron presentadas por miembros del Senado de la República e integrantes de la Cámara de Representantes: Nos referimos a los PAL 240 de 2017 (Cámara), ${ }^{25} 17$ de 2017 (Senado) ${ }_{1}^{26}$ y 55 de 2017 (Cámara). ${ }^{27}$

La redacción de estas propuestas no dista mucho de las exhibidas en años anteriores, cambiando básicamente la opción de la revisabilidad de la pena, y en otras, la indicación del catálogo de delitos a los que les sería aplicable la pena sugerida.

Dentro de estas iniciativas, se presenta el mismo fenómeno de la coincidencia conceptual al que ya aludimos; para el caso del PAL, 240 de 2017 (Cámara) y 55 de 2017 (Cámara), éstos conservan idéntica redacción a la del texto propuesto en los PAL 204 y 029 de 2015 (Cámara). El PAL 17 de 2017 (Senado), translitera el texto presentado por esa misma célula legislativa, en el PAL 12 de $2016 .{ }^{28}$

Respecto al trámite surtido en cada uno de los proyectos relacionados, el primero de ellos (PAL 240 de 2017), fue archivado por vencimiento de términos, habiendo simplemente conseguido la publicación de su contenido. El PAL 17 de 2017, además de su publicación en gaceta, consiguió que fuera presentada ponencia para primer debate, no obstante, al final corrió la misma suerte del primero. El PAL 55 de 2017, pese haber sido publicado y haberse presentado ponencia para primer debate, fue retirado por decisión del autor de la iniciativa. ${ }^{29}$

23 El Proyecto de Acto Legislativo también fue conocido como Ley Yuliana Samboní; menor víctima, que fue violada y asesinada vilmente, hecho ante el que la que la comunidad y los medios de comunicación fijaron de forma relevante su atención. El texto sometido a consideración fue el siguiente: Artículo 34. Se prohíben las penas de destierro, confiscación y prisión perpetua.

La prisión perpetua sólo será admisible como pena cuando la víctima de los delitos de homicidio, acceso carnal violento, secuestro, explotación sexual o feminicidio, sea un menor de 14 años o menor de 18 años con discapacidad.

Artículo $2^{\circ}$. La ley desarrollará el presente acto legislativo.

24 Vid. Gaceta del Congreso No. 1104 de 2016.

25 Vid. Gaceta del Congreso No. 178 de 2017.

26 Vid. Gaceta del Congreso No. 308 de 2017; ponencia para primer debate Gaceta del Congreso No. 504 de 2017. Propuesta nuevamente conocida como Ley Yuliana Samboní

27 Vid. Gaceta del Congreso No. 640 de 2017; ponencia para primer debate Gaceta del Congreso No. 890 de 2017, y posteriormente retirada por el autor - Gaceta 18 de 2018.

28 Por lo que consideramos inoficioso citar nuevamente los textos de reforma presentados.

29 Fuente: https://congresovisible.uniandes.edu.co/proyectos-de-ley/ppor-medio-del-cual-se-modifica- 
118 Prisión perpetua en Colombia. Análisis de las Iniciativas Legislativas para su autorización, y de los argumentos "racionales» para su incorporación en el ordenamiento colombiano

EMiro Cáceres-González

Llegado el 2018, encontramos en las gacetas del Congreso dos registros con pretensión similar a la que venimos aludiendo. Una de estas propuestas, el PAL 223 de 2018 (Cámara), ${ }_{1}^{30}$ presenta un contenido quizás un poco más definido sobre el alcance de la reforma pretendida, pero su exposición de motivos ${ }^{31}$ presenta información desactualizada y reiterada en anteriores proyectos. ${ }^{32}$

Sobre el avance del proyecto presentado, veremos que al igual que muchas de las proposiciones de acto legislativo presentadas, consiguió ponencia positiva para primer debate, sin embargo, corrió el mismo destino que sus antecesores, al ser archivado por tránsito de periodo legislativo.

La segunda propuesta, es el PAL 066 de 2018, ${ }^{33}$ la que tuvo mas trámite que las anteriores, pues, pese a contar con dos ponencias negativas $-{ }^{34}$ consiguió que se diera primer debate en la Comisión Primera de la Cámara con las ponencias positivas restantes ${ }^{35}$ y fuera aprobado su contenido, ${ }^{36}$ dando curso a la presentación de ponencia para segundo debate, contando con parlamentarios que la respaldaban ${ }^{37}$ y otros que -en minoría- la rechazaban, ${ }^{38}$ tal como quedó registrado en sus respectivas ponencias. Al final, esta propuesta no alcanzó segundo debate al haberse vencido los términos

el-articulo-34-de-la-constitucion-politica-suprimiendo-la-prohibicion-de-la-pena-de-prision-perpetuacadena-perpetua/9006/\#tab=2 (consultado el 25/01/2019).

30 Vid. Gaceta del Congreso No. 134 de 2018; ponencia para primer debate Gaceta del Congreso No. 210 de 2018, finalmente, archivada por tránsito de legislatura. Fuente: https://congresovisible. uniandes.edu.co/proyectos-de-ley/ppor-medio-del-cual-se-modifica-el-articulo-34-de-laconstitucion-politica-suprimiendo-la-prohibicion-de-la-pena-de-prision-perpetua-permite-la-cadena-perpetua/9297/\#tab=2 (consultado el 25/01/2019).

31 Como ya lo anunciamos, el contenido de las exposiciones de motivos se abordará infra.

32 La adición propuesta al artículo 34 es la siguiente: De manera excepcional, cuando se cometan los delitos de homicidio doloso, acceso carnal violento y abusivo, inducción y constreñimiento a la prostitución, proxenetismo y secuestro cometidos contra menores de 14 años o contra menores de 18 años con discapacidad física y/o mental, se podrá imponer hasta la pena de prisión perpetua.

En todo caso, la pena será revisable en un término de veinte (20) años en los términos que establezca la ley.

33 Vid. Gaceta del Congreso No. 667 de 2018.

34 Vid. Gaceta del Congreso No. 752 y 778 de 2018.

35 Vid. Gaceta del Congreso No 760 de 2018, ponencia para primer debate.

36 Vid. Gaceta del Congreso No. 974 de 2018.

37 Vid. Gaceta del Congreso No. 975 de 2018.

38 Vid. Gaceta del Congreso No. 987 de 2018 
para su tramitación, razón por la que fue archivada. ${ }^{39 / 40}$

En 2019, encontramos los PAL 352, ${ }^{41} 047,{ }^{42} 001^{43}$ y $614 .{ }^{44}$ Con estos proyectos, se cierra -por el momento- el periplo legislativo de intentos de modificación constitucional para introducir la pena perpetua bajo la modalidad revisable. ${ }^{45}$ Dentro de las actuaciones adelantadas en favor de estas proposiciones legislativas, tenemos que, para el PAL 352 se presentó propuesta positiva para primer debate, ${ }^{46}$ la que tuvo contraargumento mediante presentación de ponencia negativa, con la que se pidió su archivo. ${ }^{47 / 48} \mathrm{El}$ resultado final del trámite surtido para esta iniciativa, fue su retiro sin debate por parte del autor de esta. ${ }^{49}$

Seguidamente, el PAL 406, fue presentado con similar contenido al anterior, sin embargo, a la fecha esta iniciativa no ha sido discutida ni retirada, quizás por cuestiones de tránsito de periodo legislativo.

Finalmente, con relación a los PAL 047 y 001, debe precisarse que el primero de

39 Fuente: https://congresovisible.uniandes.edu.co/proyectos-de-ley/ppor-medio-del-cual-se-modifica-elarticulo-34-de-la-constitucion-politica-suprimiendo-la-prohibicion-de-la-pena-de-prision-perpetua-yestableciendo-la-prision-perpetua-revisable--en-memoria-de-gilma-jimenez-suprime-la-prohibicion-dela-pena-de-prision-perpetua/9494/\#tab=2 (consultado el 11/02/2019).

40 La adición presentada para debate es la siguiente: De manera excepcional, cuando se cometan los delitos de homicidio doloso, feminicidio, secuestro y acceso carnal violento cometidos contra menores de 14 años o contra menores de 18 años con discapacidad física y/o mental, se podrá imponer hasta la pena de prisión perpetua.

En todo caso, la pena será revisable en un terminó de treinta (30) años en los términos que establezca la ley.

41 Vid. Gaceta del Congreso No. 173 de 2019.

42 Vid. Gaceta del Congreso No. 669 de 2019.

43 Vid. Gaceta del Congreso No. 664 de 2019.

44 Vid. Gaceta del Congreso No. 614 de 2019.

45 Estando el presente artículo en proceso de revisión para su publicación, se presentaron los tres últimos PAL mencionados, por lo que, se ha actualizado su contenido en lo que se consideró más relevante a los intereses de nuestro trabajo.

46 Vid. Gaceta del Congreso No. 326 de 2019.

47 Vid. Gaceta del Congreso No. 321 de 2019.

48 Como aspecto a destacar de los dos últimos PAL, deben relievarse las ponencias negativas presentadas por un sector de los ponentes designados para su trámite, ya que en los PAL anteriores, no se presentó ponencia negativa en ninguno de los proyectos.

49 Fuente: https://congresovisible.uniandes.edu.co/proyectos-de-ley/por-medio-del-cual-se/9922/\#tab=2 (consultado el 22/05/2019). 
120 Prisión perpetua en Colombia. Análisis de las Iniciativas Legislativas para su autorización, y de los argumentos "racionales» para su incorporación en el ordenamiento colombiano

Emiro Cáceres-González

ellos fue acumulado a su homólogo, y a pesar de contar con ponencias positivas ${ }^{50}$ y negativas ${ }^{51}$ en primer debate, su contenido ha sido aprobado,52 actualmente cuenta con nueva ponencia negativa ${ }^{53}$ para segundo debate, y su estudio está pendiente de discusión en la Cámara de Representantes, por lo que su destino es incierto.

En suma, el anterior recorrido nos muestra que los intentos del legislador por hacer de la prisión permanente revisable en Colombia una realidad, no han sido pocos. De la trazabilidad efectuada, se advierte que, pese a la corta edad de la Constitución, al menos, desde hace 12 años, se ha venido trabajando por modificar la prohibición de penas perpetuas, para conseguir que esa limitación, deje de ser piedra en el zapato, para un legislador populista, que pretende imponer penas aún más graves de las que se tienen hasta el momento, ${ }^{54}$ las que pueden alcanzar los sesenta años, pero que a su juicio, son insuficientes para generar esa sensación de seguridad que tanto implora la ciudadanía.

\subsection{Motivos ofrecidos por el legislador para justificar la introducción de la prisión permanente revisable}

En este segmento, mencionaremos los apartes más relevantes de las exposiciones de motivos presentadas a partir del 2007, y que, entre otras, constituyen una constante en el tiempo, de iniciativas sin propuestas nuevas. Haremos mención además, a las ponencias y debates surtidos en el curso de las etapas del proceso legiferante.

En un análisis al ejercicio legislativo realizado sobre este tema, las conclusiones, no pueden ser menos que calificadas de desafortunadas. Los puntos comunes que emergen de ellas podrían resumirse en: 1). La existencia de un debate binario en el que se yuxtapone una relación, ciudadano/enemigo, ${ }^{55} 2$ 2). La pretensión legisladora para ese enemigo, no ciudadano, es, mantenerlo lo más alejado posible de la sociedad, la que le

50 Vid. Gaceta del Congreso No. 752 de 2019.

51 Vid. Gaceta del Congreso No. 744 de 2019.

52 Vid. Gaceta del Congreso No. 1004 de 2019.

53 Vid. Gaceta del Congreso No. 1038 de 2019.

54 Sobre populismo punitivo, la información es abundante, sin embargo, se recomiendan los textos de Larrauri, Elena "Populismo punitivo...y como resistirlo", en Revista Jueces para la democracia, No. 55, marzo de 2006; Pratt, Jhon, Penal populism. Londres y Nueva York, Routledge, 2007; Robert, Julián Stalans, Loretta, Indermaur, David, Hough, Mike, Penal populism and public opinión. Lessons from five countries, Nueva York, Oxford University Press, 200; Sozzo, Máxımo, "Populismo punitivo, proyecto normalizador y "Prisión-Depósito" en Argentina, en Sistema penal \& Violencia. Revista electrónica da Facudade de Dereito, Volume 1, Número 1, p. 33-65 - julho - dezembro, 2009. 
considera como irresocializable; 3). El permanente aumento de la conminación penal, muchas veces con fines electorales, a fin de venderle a la sociedad, una falsa idea de seguridad y hacerle creer que le preocupan sus demandas; 56 y, 4). La -recurrente- falta de racionalidad en el debate legislativo, el carente sustento empírico para soportar las afirmaciones que incorpora en sus exposiciones de motivos, ponencias y debates. ${ }^{57}$

Demostraremos nuestras afirmaciones comenzando con el PAL 023 de 2007 (Cámara) ${ }^{58}$ el que, en la exposición de motivos, hace evidente la falta de interés de los impulsores de la iniciativa, por buscar mecanismos ajenos al derecho penal, con los que se pueda intentar mejorar la presunta situación disfunciona ${ }^{59}$ que a su juicio precisa de intervención legislativa.

Pareciera que, para sus impulsores solo es útil el derecho penal como alternativa de control social, ya que incluso, en su EM dejan entrever, una especie de desprecio por la educación como medio de control; allí se consagra que:

la causa de todo mal está en la falta de educación, pero debe observarse que los teatros de mayor criminalidad son precisamente aquellos centros en donde la cultura social arroja un índice relativamente superior. Años atrás, cuando el país disponía de menos elementos de cultura, la criminalidad era inferior, lo cual significa, sencillamente, que la educación rudimentaria e incipiente que el estado proporciona es incapaz de infundir en el alma de nuestro pueblo sentimientos que contrarresten sus instintos naturales de perversión $(\ldots)^{60}$

A pesar de que el aparte citado afirma que la educación ofrecida por el Estado se caracteriza por ser incipiente, y que por ello no contrarresta los instintos naturales de la sociedad, es reprochable que no ofrezca como alternativa, el fortalecimiento del sistema educativo, o la realización de campañas de educación, sensibilización 0

56 Silva Sánchez, Jesús María, La expansión del derecho penal, aspectos de la política criminal en las sociedades posindustriales, Madrid, Edisofer, 2011.

57 Sobre la falta de racionalidad legislativa ver entre otros, DíEz Ripoltés, José LuIs, La racionalidad de las leyes penales, práctica y teoría, Madrid, Trotta, 2013, BecerRa Muñoz, José, La toma de decisiones en política criminal: Bases para un análisis multidisciplinar, Valencia, Tirant Lo Blanch, 2013, SoтомAYoR Acosta, Juan Oberto, "Las recientes reformas penales en Colombia: Un ejemplo de irracionalidad legislativa", en Nuevo Foro Penal, No. 71, 2007, pp. 13-66, más modestamente, Cáceres González, Emiro, Derecho Penal y Derecho Administrativo Sancionador: Elementos de racionalidad legislativa, Bogotá, Leyer, 2018, el mismo, "(I)racionalidad legislativa en la concepción de la Prisión Permanente Revisable en España", en Revista Brasileira de Ciências Criminais, vol. 148, octubre de 2018, pp.18-54.

58 Cfr. Gaceta del Congreso No. 339 de 2007.

59 Díez Ripollés J. L. La racionalidad (...) Op. Cit., p. 18-19.

60 Vid. Gaceta del Congreso No. 339 de 2007. 
122 Prisión perpetua en Colombia. Análisis de las Iniciativas Legislativas para su autorización, y de los argumentos "racionales» para su incorporación en el ordenamiento colombiano

EMIRo Cáceres-González

capacitación para los diversos sectores sociales a fin de que conozcan sus derechos, deberes y prohibiciones; por el contrario, la solución a dicha precariedad, es decir, el placebo legislativo sugerido es, el ofrecimiento de más derecho penal, el de una mayor criminalización mediante una política de cero tolerancia, sin alternativas de prevención, dejando así la percepción de que los demás mecanismos de control social, sencillamente son inútiles, no funcionan, o nunca han funcionado, pero que con el derecho penal no sucede eso. Como puede notarse, el autor de la iniciativa se apoya en argumentos falaces al aludir a la inutilidad de la educación y a la conveniencia del uso del aparato represor, puesto que no aporta el más elemental estudio social, criminológico, o de algún campo del conocimiento, con el fin de respaldar su tesis, bastándole simplemente sus conclusiones, para seguir adelante con su afán criminalizador, dejando entrever así, la anticipación de la poca altura científica, rigor y seriedad con que se adelantarían las discusiones legislativas sobre este tópico.

Seguidamente, el documento refuerza su postura trayendo casos que causaron gran repercusión e impacto mediático a nivel nacional, citando entre ellos el caso del confeso violador y asesino de niños, Luis Alfredo Garavito, el cual, el pre legislador capitaliza para criticar lo que considera como el flexible y mediocre sistema judicial, el que, a su modo de ver, en el corto plazo le permitirá a este sujeto, que «pronto salga libre de la cárcel, pagando solo 11 de los 15 años a los que fue condenado, gracias a la unificación de penas ${ }^{61}(\ldots)$. Eso sin contar que 15 años son muy poco castigo para los crímenes atroces que cometió este individuo, que en otro país, ya estaría condenado a cadena perpetua o pena de muerte», por lo que se hace necesario «replantear la política criminal y todas aquellas políticas que resultan conexas para la prevención de estas conductas ya que «las autoridades responsables de aplicar la rigurosidad de la ley, ya no pueden controlarlo y se hace necesario diseñar y adoptar una política integral para combatir dicha problemática en esta materia».

Como vimos al inicio del análisis de este PAL, el legislador menciona en su exposición de motivos la necesidad de crear una política integral y preventiva, sin embargo, al revisar la propuesta, no se observa articulado que la desarrolle; en su lugar, solo la menciona como argumento marginal, pues su única intención es la de imponer la medida de prisión perpetua, que además, sólo sería revisada, cuando haya cumplido un periodo de privación efectiva de la libertad de 35 años. Aunado a esto, al menospreciar la educación como alternativa de control social, se descarta la posibilidad de rebaja

61 Sobre el tiempo de privación efectiva de la libertad y la cuantía de la pena impuesta a este sujeto, diremos, simplemente, que el señor Garavito se encuentra purgando su pena desde 1999 y a la fecha no goza de beneficio o rebaja por estudio o trabajo, por lo que puede afirmarse que no es cierto que la pena que le fue impuesta sea la aludida por el autor de la iniciativa legislativa. 
por estudio como opción resocializadora durante el tratamiento intramural. Como si esto fuera poco, consagra la creación de un Registro Nacional de Violadores con el que, en caso de que sea posible conseguir la libertad, y pasado el plazo mencionado de purga de condena efectiva, los datos del sancionado permanecerán, en un registro perpetuo, que arrastra por lo tanto una sanción imborrable, en perjuicio de quien ya ha sido sancionado por su conducta.

Concerniente al sustento utilizado para invocar la necesidad del aumento punitivo, la exposición de motivos trae unas estadísticas al parecer elaboradas ${ }^{62}$ por el Instituto Colombiano de Medicina Legal (IML) de los exámenes sexológicos practicados a hombres y mujeres víctimas de abuso o violencia. Lo llamativo de este sustento, es que adjunta información recopilada en el año 2001, en una propuesta legislativa presentada en 2007, situación que da cuenta del poco interés del legislador por procurar otras fuentes de apoyo, y utilizar información desactualizada para sostener un hecho reportado como recurrente, irregular y en constante aumento. Por fin, clausura su exposición criticando a los aplicadores de justicia, los que a su parecer, ya no pueden controlar este tipo de delincuencia.

Se insiste en la pena a perpetuidad, apelando a argumentos periféricos que constituyen obiter dicta, para legitimar su única intención, que no es otra que hacer notorio un evidente discurso de odio hacia el delincuente, quien debe pagar con la pérdida indefinida de su libertad, para satisfacer el deseo de vendetta de la sociedad y el ánimo populista del creador de la ley, a quien el ideal resocializador pasa a un plano residual.

La ponencia presentada para primer debate, ${ }^{63}$ alaba el sustento estadístico ofrecido en la exposición de motivos, al considerar que dicha propuesta ha sido

el producto de una extensa y juiciosa investigación, que llevó a determinar con precisión el alto grado de vulnerabilidad de nuestros menores y en consecuencia, la necesidad de crear un ordenamiento jurídico lo suficientemente fuerte en la imposición de las sanciones y acorde con la gravedad que significa la violación a los derechos de los niños $(a s)^{64}$ (...) por lo que, lo pretendido con esta reforma, no es otra cosa que la loable labor de (...) disminuir la problemática de la violación sexual cometida en los niños colombianos. ${ }^{65}$

62 Decimos "al parecer", debido a que el legislador no suministra la fuente de donde extrae dicha información.

63 Cfr. Gaceta del Congreso No. 519 de 2007.

64 Ibídem.

65 Ibíd. 
124 Prisión perpetua en Colombia. Análisis de las Iniciativas Legislativas para su autorización, y de los argumentos "racionales» para su incorporación en el ordenamiento colombiano

EMIro Cáceres-González

La retórica del argumento nuevamente es el ofrecimiento de la prisión permanente revisable, como solución a la comisión de delitos sexuales cometidos, especialmente en menores de edad; sin embargo, ante la ausencia de estudios criminológicos y sociológicos, así como el desinterés por procurar alternativas de prevención e indagación sobre las causas que generan este tipo de delincuencia, la panacea legisladora, se convierte en un mero placebo legislativo con el que se pretende ofrecer una solución aparente a las presiones sociales; especialmente, para apaciguar a los grupos de víctimas, con alternativas que en el fondo, en nada resuelven el problema. De hecho, la ligereza con que trata de justificar el tema el legislador, le alcanza para sostener de manera totalizante y sin fundamento que

científicamente está demostrado que los individuos que cometen de manera compulsiva el delito de violación o acceso carnal violento con menores, son sujetos que presentan serios trastornos psicológicos, emocionales y de personalidad» los que, "en la totalidad de los casos las lesiones son originadas en la infancia por dramáticas vivencias familiares, estas lesiones psicológicas desembocan en conductas incontrolables y en la gran mayoría de los casos, inconscientes. ${ }^{66}$

A pesar de sus conclusiones, el autor de la iniciativa no se preocupa por modificar esta percepción mediante el desarrollo de una nueva y mejor política pública preventiva, sino, por el contrario, encuentra en el derecho penal la solución mágica a este problema social.

En el caso del PAL 163 del 2008, ${ }^{67}$ la EM constituye un giro adicional a la tuerca, para hacer aún más evidente la intención de tratar a los delincuentes sexuales como enemigos de la sociedad.

De su lectura, se observa que a estos individuos se les niega cualquier posibilidad de retorno al seno de la sociedad, atendiendo a la gravedad de su conducta, castigo que reciben, como justa retribución por el mal causado, sin que para estos delincuentes se persiga una pretensión resocializadora. Esta conclusión se desprende de la introducción descrita en la exposición de motivos, la que pretende «abrir la posibilidad al Juez, al determinar la gravedad del delito, de considerar que la pena a imponer no tenga una función rehabilitadora permitiendo la imposición de una sanción que en términos temporales sea equivalente a la vida del delincuente». ${ }^{68}$

66 Cit.

67 Vid. Gaceta del Congreso No. 685 de 2008.

68 Ibídem. 
La anterior cita, constituye una sustitución de la Constitución ${ }^{69}$ con la que se establece implícitamente una doble estratificación punitiva, entre delincuentes con probabilidad legal y constitucional de ser resocializados, y de delincuentes que, de forma automática no cuentan con tal posibilidad, al ser considerados seres irresocializables sin posibilidad de cambio.

Este proyecto, acude de nuevo a argumentos cliché, cuyo fin es dar fuerza a la proposición de reforma constitucional, pero sin intención de intervención legislativa concreta. Tales frases retóricas corresponden a afirmaciones como:

Es crucial que invirtamos en los niños más que en cualquier otro grupo, porque su felicidad por sí sola, producirá la sociedad que anhelamos. (...) Por lo anterior, es vital que el Estado invierta todos sus esfuerzos económicos, políticos y jurídicos en la noble intención de crear un medio social sano desde todo punto de vista (...) la laxitud legal y la debilidad de nuestro sistema penal, la inoperancia de las instituciones responsables de la protección de los derechos de los niños, la doble moral, la permisividad social e institucional generalizadas en todo nuestro territorio, la falta de una política pública en materia de planificación familiar, son entre otras, algunas de las causas para que la violación de los derechos de los niños sean una constante en nuestro país. ${ }^{70}$

Lo anterior, evidencia que la coherencia argumentativa en la exposición de motivos, no guarda correspondencia con el articulado que propone la reforma; la redacción propuesta -la cual será finalmente, la que vincule al legislador, al aplicador del derecho y la ciudadanía en general-, en ninguna parte, desarrolla los presuntos esfuerzos económicos, políticos y jurídicos en los que no debe escatimar el Estado, para conseguir un medio social sano para nuestra infancia; notándose por el contrario, que la única finalidad pretendida, es -ex novo- la de intentar mantener a ese sujeto objeto de desprecio (delincuente/enemigo), lo más alejado posible de la sociedad, ante un Estado incapaz de plantear mejores soluciones para éste. ${ }^{71}$

69 Sobre sustitución de la constitución pueden consultarse entre otras las sentencias C-551 de 2003, C-1200 de 2003, C-970 de 2004, C-1040 de 2005, C-579 de 2013 y C-397 de 2010, ésta última, más cercana al objeto de nuestra investigación, ya que en ella se efectuó control previo de constitucionalidad a la ley 1327 de 2009, la que convocaba un referendo para modificar el artículo 34 de la Constitución y permitir penas perpetuas a los delincuentes sexuales.

70 Vid. Gaceta del Congreso No. 685 de 2008, exposición de motivos del PAL 163 de 2008.

71 De hecho, la EM señala que las penas señaladas en el código penal para este tipo de delitos son bajas, y que los beneficios señalados en la norma procedimental son inconvenientes, por lo que «el Congreso debe entender de una vez por todas que el fortalecimiento de las penas relacionadas con delitos cometidos en menores de edad es una tendencia mundial y una necesidad inaplazable». Ibídem. 
126 Prisión perpetua en Colombia. Análisis de las Iniciativas Legislativas para su autorización, y de los argumentos "racionales» para su incorporación en el ordenamiento colombiano

EMiro Cáceres-González

Al final, la exposición de motivos añade un título que rotula como costo social para el Estado. En este título se esperaría que, el pre legislador se ocupara de exponer el impacto que puede generar la modificación constitucional, el análisis de los resultados esperados, y el costo económico que supondría tal modificación; sin embargo, los párrafos allí consignados, a lo sumo se conforman con aludir que

debe ser una prioridad hacer una reflexión política, jurídica y económica de la proporcionalidad de las penas actualmente existentes en Colombia y la gravedad de los delitos, por cuanto las penas como están planteadas actualmente por nuestra legislación para reprender delitos que atentan contra nuestros niños, no son ejemplarizantes, ni producen un desestimulo efectivo en el individuo que pretende cometer el acto delictivo ${ }^{72}(\ldots)$ se debe replantear el carácter de la pena en nuestra sociedad, pues los delincuentes responden a los cambios ocurridos en los costos de oportunidad; es decir, en la probabilidad de aprehensión, en la severidad del castigo y en otras variables relevantes como si fuesen efectivamente los calculadores racionales del modelo económico (...) lo que significaría en todos los casos que la sanción penal debería calcularse de tal modo que el delincuente con la comisión del delito empeore ostensiblemente su situación. ${ }^{73}$

Nuevamente, aquí se esperaría cierta coherencia en las apreciaciones del legislador, con lo cual, si está haciendo referencia a los costos de oportunidad y a la probabilidad de aprehensión, debería ocuparse del reforzamiento de los mecanismos de investigación y sanción de estas conductas, a fin de reducir índices de impunidad y en su remplazo ofrecer alternativas de persecución y sanción, mas no, a aumentos de pena. Recordemos que, como ya lo dijo hace varios lustros el Marqués de Beccaría: Uno de los mayores frenos de los delitos, no es la crueldad de las penas, sino su infalibilidad y, por consecuencia la vigilancia de los magistrados y la severidad de un juez inexorable, que para ser virtud útil debe ir acompañada de una suave legislación, la certeza de un castigo, aunque esta sea moderada, hará siempre mayor impresión que el temor del más terrible, pero unido a la esperanza de la impunidad. ${ }^{74}$

72 Pese a indicar que las penas existentes no intimidan lo suficiente al destinatario de la prohibición, no aporta información que sustente las razones por las que cree que, con esta nueva modificación se conseguirá el efecto disuasorio esperado.

73 Cit.

74 Vid. Beccaria, Cessare, De los delitos y de las penas (Traducción y notas de Francisco Tomás y Valiente), Barcelona, Orbis, 1984, pp. 82-83. 
De otro lado, podríamos afirmar que nos encontramos ante un aparente desinterés de quien ha sido designado como ponente de la iniciativa. Nos referimos a la desidia mostrada para analizar y ofrecer ideas propias, ya que el escrito de ponencia coincide íntegramente con la exposición de motivos, limitándose a citar literalmente el texto presentado, lo cual pone en evidencia la falta de seriedad con que trata el legislador este tipo cuestiones, las que, pese a su trascendencia, carecen de un serio debate dialéctico y científico, atendiendo al contenido de los derechos que entran en tensión y que se pretenden, de una parte proteger, y de otra restringir. ${ }^{75}$

La desidia legisladora se confirma revisando la exposición de motivos y la ponencia para primer debate, donde se alude, a un hecho sucedido en septiembre de $2007^{76} \mathrm{y}$ que se extrajo literalmente de la exposición de motivos del PAL de ese año, sin haber sido actualizada, citándose como un suceso acontecido a escasos días de presentado el nuevo proyecto de modificación constitucional (2008). El extracto al que hacemos referencia es el siguiente:

Esta semana el país se conmovió con el caso del niño Luis Santiago de 8 meses de edad, al enterarse del secuestro y posterior homicidio del niño a manos de su propio padre, en el municipio de Chía, Cundinamarca».

Este protuberante descuido, da cuenta de la ligereza con que el legislador maneja la posibilidad de incorporar la sanción penal a perpetuidad, puesto que no es un error menor que en varias de las ponencias presentadas -tal como lo mostraremos más adelante- se haga referencia a hechos ocurridos en años anteriores, como si hubieran ocurrido a escasos días de presentados los nuevos PAL, por lo que, podría intuirse que, si el legislador no se preocupa por hacer ajustes cosméticos a su nueva propuesta de reforma, tanto menos se ocupará por justificar con estudios serios y actuales, la real necesidad de intervención para permitir una sanción de tan gravosa entidad.

Llegado el 2009, se presenta ante el Congreso de la República el Proyecto de Ley 260 (Cámara) por medio del cual se convoca a un referendo constitucional y se somete a consideración del pueblo un proyecto de reforma constitucional. ${ }^{77}$

Con esta iniciativa se pretendía sincluir un inciso al artículo 34 de la Constitución Política, para hacer una excepción en nuestro ordenamiento jurídico e incorporar la

75 Recordemos que tanto el artículo 157 como el 175 de la LORC se refieren a la ponencia, y allí permiten ver el grado de preparación y conocimiento sobre la iniciativa que debe poseer el ponente, por lo que, consideramos rechazable el manejo simplista que el legislador-ponente le ha dado a tan alta responsabilidad.

76 Ver:https://www.elcolombiano.com/historico/co _ cronologia _ secuestro_ del_nino _ luis _ santiago_Icg_30092008-GEec_ 15553 (consultado el 17/02/2019).

77 Vid. Gaceta del Congreso No. 80 de 2009. 
128 Prisión perpetua en Colombia. Análisis de las Iniciativas Legislativas para su autorización, y de los argumentos "racionales» para su incorporación en el ordenamiento colombiano

EMiro Cáceres-González

pena de hasta prisión perpetua que permita castigar los delitos señalados, cuando se cometan contra nuestros niños».

La iniciativa fue presentada por varios políticos, entre los que se encontraba, a la cabeza, la entonces concejala Gilma Jiménez Gómez (O.E.P.D), quien posteriormente, y bajo esa plataforma, consigue un escaño en el Senado de la República. El argumento con el que se pretendía legitimar la aludida convocatoria de referendo para la imposición de la pena a perpetuidad, eran los apoyos obtenidos de la ciudadanía a la iniciativa, quienes por vía de firmas invocan como necesaria tal reforma.

Dentro de las razones con las que se pretendió justificar la modificación constitucional, es patente el uso del dolor de las víctimas, al igual que el rechazo manifestado por las masas, y la tesis de cero tolerancia contra la delincuencia sexual sobre menores, rememorando para ello, hechos ocurridos a infantes y adolescentes durante los años 2004 a 2009, cuestionando seguidamente si las penas existentes se consideraban suficientes 0 si por el contrario era necesaria la medida de prisión perpetua. ${ }^{78 / 79^{*}}$

\section{Ibíd.}

79 Mas adelante refuerza sus palabras, recurriendo al poder de las encuestas exprés hechas por algunos medios de comunicación a su audiencia, la cual se muestra «preocupada por estos aberrantes delitos, cometidos contra nuestros niñ@s y en consecuencia con el debate suscitado por el Referendo propuesto, le han preguntado a la opinión pública sobre los castigos que deberían imponerse a los delincuentes que violan los derechos fundamentales de los niñ@s. (sic).

URNA VIRTUAL-CARACOL TV. junio de 2008

¿Está de acuerdo con la prisión perpetua?

De acuerdo 96\% En desacuerdo 4\%

EL ESPACIO. Encuesta del 5 de septiembre de 2006.

Cree que la persona que cometa el delito de acceso carnal violento merece:

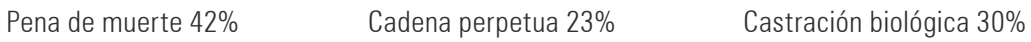

Pena actual $40 \%$

LA PATRIA ¿Qué opina de la idea de que sea impuesta en el país la castración química a los violadores reincidentes?

Es un acierto $76 \%$ Viola los derechos humanos 13\%

No es el castigo merecido 10\% Es un despropósito 1\%

PORTAFOLIO. Encuesta 17 de agosto de 2006.

¿Está de acuerdo con la pena de muerte a secuestradores?

Sí $58 \% \quad$ No $42 \%$

Vid. Gaceta del Congreso No. 80 de 2009.

* Es evidente el impacto mediático que genera este tipo de iniciativas, y el ajuste de la agenda setting por los grupos de víctimas y los grupos de presión interesados en la prosperidad de la reforma legislativa. Sobre este tema puede consultarse, Cerezo Domínguez, Ana Isabel, El protagonismo de las víctimas en la elaboración de las leyes penales, Valencia, Tirant Lo Blanch, 2010. 
Posteriormente, retoma segmentos de la exposición de motivos del PAL 163 del año 2008, utilizando frases de refuerzo sin manifestación legislativa de desarrollo; 80 y apelando a criterios de eficacia preventiva, los que señalan de forma escueta y sin sustento demostrativo, acerca de la capacidad disuasoria de esta nueva modalidad de pena al afirmar que: "sse busca con este Referendo Constitucional, contar con una estrategia preventiva, ya que su implementación y desarrollo normativo deberán impedir que los delitos que se busca castigar se continúen cometiendo».81

Como puede observarse, los autores de la iniciativa acuden al ejercicio del ius puniendi estatal, como un mecanismo preventivo, para evitar este tipo de conductas, olvidando intencionalmente, la aplicación del principio de ultima ratio. Pero es aún más censurable, que se acuda al recurso populista del ofrecimiento de sensación de seguridad, sin siquiera intentar traer bases o estudios que confirmen que la imposición de penas elevadas -las cuales, venían ya en constante aumento- generen la abstención por parte del delincuente, de cometer este tipo de conductas.

Frente al mandato de resocialización, esta propuesta, al igual que la presentada en 2008, considera ajustada a la carta, la aplicación automática de un tratamiento diferenciado entre delincuentes resocializables y no resocializables -0 como los catalogamos en párrafos anteriores, entre delincuentes de primera y segunda categoría,$^{82}$ y que ello per se, no genera una vulneración ni una sustitución de la Constitución, sino simplemente

una innovación en nuestra estructura constitucional y un profundo cambio en la idea de la finalidad de las penas y de nuestro sistema de derecho punitivo [por lo que se hace imperioso] hacer la reflexión social, política, jurídica y económica de la proporcionalidad de las penas actualmente existentes en

80 Nos referimos nuevamente, al uso del argumento de la laxitud legal, la debilidad del sistema penal, la inoperancia institucional de los encargados de proteger los derechos de los niños, la doble moral, la permisividad social e institucional y la falta de una política pública en materia de planificación familiar. Vid. Gaceta del Congreso No. 80 de 2009.

81 Ibídem. De estrategia preventiva que pretende evitar que se sigan cometiendo este tipo de delitos, la rótula la ponencia presentada para primer debate. Gaceta del Congreso No. 182 de 2009.

82 Reza la exposición de motivos que «se propone un cambio profundo en la estructura constitucional colombiana y en el ordenamiento jurídico en general, estableciendo una excepción (negrilla original) a la prohibición de imponer la pena de prisión perpetua. Considerando que los delitos que enuncia esta exposición de motivos del Referendo merecen el repudio y el castigo total de la sociedad, por afectar su núcleo mismo; abriéndole la posibilidad al Juez, una vez la ley reglamente la Reforma, al determinar la gravedad del delito, de considerar que la pena a imponer no tiene una función rehabilitadora, en la medida que los delitos cometidos dejan secuelas irreversibles y daños irreparables y se cometen dolosamente, permitiendo la imposición de una sanción que en términos temporales sea equivalente a la vida misma del delincuente». Ibíd. 
130 Prisión perpetua en Colombia. Análisis de las Iniciativas Legislativas para su autorización, y de los argumentos "racionales» para su incorporación en el ordenamiento colombiano

EMIro Cáceres-González

Colombia y de la gravedad de los delitos que se cometen contra nuestros niños, por cuanto las penas como están concebidas actualmente en nuestra legislación no son ejemplarizantes, ni producen un desestimulo efectivo en el individuo que pretende la comisión del delito. ${ }^{83}$

Al final de la EM se registra un argumento desde todo punto de vista violatorio, no solo del ejercicio del derecho de defensa, sino también de la presunción de inocencia, cuyo pilar se encuentra erigido constitucionalmente en favor de cualquier procesado. En dicho documento se arguye que

los procedimientos en los procesos penales establecidos por la ley, por ejemplo cuando se judicializa a un adulto por delitos contra los niños, especialmente los sexuales, están llenos de posibilidades, para que los defensores de los sindicados dilaten y desvíen los procesos. Acudiendo a estrategias, muchas soportadas legalmente y con incomprensibles contradicciones en la interpretación de la ley, logran[do] vencimientos de términos o hacerlos excesivamente largos, en detrimento de las víctimas, lo que implica para el denunciante en términos económicos y emocionales durar años en este tipo de eventos tan dolorosos. ${ }^{84}$

Dentro de esta afirmación se oculta un argumento que, a nuestro juicio, no soportaría siquiera un análisis superficial de constitucionalidad, y es el relativo a la implantación de un régimen de responsabilidad objetiva. Consideramos que ello es así, cuando en la propuesta de reforma, se sugiere limitar el correcto ejercicio del derecho defensa y el respeto del principio a la presunción de inocencia bajo argumentos dirigidos a cuestionar aspectos legislativos de garantía, registrados en la Ley y creados por el mismo legislador por expreso mandato constitucional..$^{85}$

En este sentido, los impulsores de la iniciativa, ven como un privilegio innecesario, que a los enjuiciados se les garantice el debido proceso, pues ello solo genera, posibilidades incómodas, dilaciones, desvíos y estrategias que no deberían contemplarse para este tipo de -enemigos- delincuentes, pues ello solo genera, molestos vencimientos de términos y/o procesos excesivamente largos.

Y no es que pretendamos asumir una aparente postura de excesiva benignidad 0 complacencia hacia los autores de tan deplorables actos; lo que queremos apreciar, es

83 Vid. Gaceta del Congreso No. 80 de 2009.

84 Vid. Gaceta del Congreso No. 182 de 2009.

85 Nótese que, lo que se pone en entredicho por los autores de la iniciativa, no es la incursión por los abogados, de dilaciones que pudieran considerarse como injustificadas, sino el recurso a estrategias, muchas soportadas legalmente y con incomprensibles contradicciones en la interpretación de la ley 
que no consideramos recomendable el uso del aparato legislativo para con el coartar, de manera automática, garantías -que tantas luchas han costado a través de los siglos, y que constituyen conquistas que deben ser irrenunciables-. Por esta razón, si en un determinado caso, se llegare a estimar, que los sujetos procesales están dilatando intencionalmente el procedimiento jurisdiccional, estará en manos del juez de la causa, hacer uso de sus poderes de corrección, a fin de llevar a buen puerto el desarrollo de las audiencias; 0 , en el peor de los casos, si se pensare que todos los sujetos intervinientes han dilatado malintencionadamente la actuación judicial y que con ella se puede generar un perjuicio a la víctima, siempre habrá lugar al uso de las instancias disciplinarias para que se investigue el actuar de quienes participaron en el procedimiento penal -incluido el juez-, pero no será mediante la limitación de garantías por vía constitucional o legislativa, que se conseguirán condenas oportunas y efectivas en contra de estas conductas.

Pero lo más cuestionable de esta manifestación, es el hecho de que, este tipo de propuestas, en vez de buscar alternativas que permitan identificar las causas periféricas del represamiento del sistema penal y por lo tanto, la proposición de opciones para su fortalecimiento, persiga una especie de juicio penal exprés, en el que, además, se permita pasar por encima de la presunción de inocencia, y que complementariamente, sea permitido imponer como pena, la limitación perpetua de la libertad, bajo el cobijo de que estas conductas constituyen una ofensa social inaceptable e imperdonable, ${ }^{86} \mathrm{como}$ si nos encontráramos frente a un Estado encargado, no de administrar justicia, sino de perdonar pecados a sus conciudadanos.

Para reforzar el argumento legitimador de la necesidad de imponer este tipo de penas contra estos antisociales, ${ }^{87}$ la autora de la iniciativa acude a un adicional argumento populista a fin de ambientar el debate legislativo: Al momento de su intervención deja constancia de que allí se encuentra presente la madre de la más reciente víctima de la época; buscando con ello causar un impacto emocional y televisivo sobre quienes tienen la obligación de dar trámite a la iniciativa. Así quedó registrado en el acta de comisión primera permanente, donde la señora Gilma Jiménez anunció:

(...) le quiero dar la bienvenida a Ivón Lozano, que es la mamá de Santiago, viene de la audiencia de rebaja de penas de Pelayo y ha sido un baluarte fundamental, aquí están sus Representantes Ivón, los que van a hacer

86 Vid. Gaceta del Congreso No. 182 de 2009.

87 Así los rotulan en el acta de la comisión primera permanente -legislatura 2008-2009-, donde el Representante David Luna indica que con esta reforma los Jueces «tendrán la posibilidad de condenar a estos delincuentes, a estos antisociales hasta por prisión perpetua». Vid. Gaceta del Congreso No. 547 de 2009. 
132 Prisión perpetua en Colombia. Análisis de las Iniciativas Legislativas para su autorización, y de los argumentos "racionales» para su incorporación en el ordenamiento colombiano

Emiro Cáceres-González

posible que podamos salir a castigar a los Pelayos con la prisión perpetua, sin lugar a duda. ${ }^{88}$

Con esta alusión se hace notoria la influencia y el protagonismo que los grupos de víctimas pueden ejercer sobre el parlamento, ya que, evidentemente, no es políticamente rentable oponerse a este tipo de iniciativas, aun cuando se crea que jurídicamente son inconvenientes. Así lo deja entrever uno de los senadores que participaron en el debate, quien al momento de hacer uso de la palabra expone algunos argumentos que, en principio dieran a pensar que su voto va a ser negativo; sin embargo, luego de su disertación toma una decisión diversa, anunciando:

(...) hay que decir y esto para los abogados y para los juristas, y para los profesores de derecho, que entendemos la profunda preocupación que significa para ellos que nos atrevamos a poner en la Constitución, a inscribir en ella la pena de prisión perpetua; entendemos la preocupación, sabemos que esto implica un profundo debate que para algunos esto es un retroceso importante en el desarrollo moderno del derecho que nos devuelve al debate sobre las características y las funciones de la pena, (...) hay unas corrientes digamos liberales del derecho que hay que recoger y hay que pensar en ellas; a mí me tranquiliza bastante la modificación que se ha inscrito que le permite al juez hacer esa proporcionalidad de la pena, pero también queda claro que con esta decisión honorables Colegas de la Comisión Primera, estamos tomando partido por la pena como castigo, estamos asegurando que en estos casos del maltrato, del abuso, de la violación, del asesinato de niños y niñas, estamos garantizando el aislamiento y el castigo y no la resocialización del individuo (...)..$^{89}$

Con lo anterior, podría decirse que, como legisladores, tienen claro que ciertas garantías -como el principio de resocialización- pueden verse comprometidas seriamente; pero que, política y electoralmente es más beneficioso, atender al llamado clamor social, que atender a las voces de una dogmática penal, que no constituye un universo representativo en materia de votos.

88 Podría pensarse que el reflejo de este mecanismo de presión se vio automáticamente manifestado en las votaciones de los miembros de la célula legislativa, tal es el caso del Representante Guillermo Rivera, quien sostuvo: «algunos han dicho que este proyecto es en cierta medida una apelación a la ley de la selva, a la ley del ojo por ojo, a la ley del diente por diente, a la ley del Taleón (sic). Yo creo que quienes piensan de esa manera doctor Roy, están pensando en el victimario, si esta iniciativa se examina desde la perspectiva de la víctima, lo que estamos haciendo es una protección extrema de un sector de la población que tiene condiciones de vulnerabilidad por su estado de formación, por su condición de infante, por su condición de indefensión. De tal manera que esta iniciativa, yo la considero como una iniciativa de clara inspiración liberal (...)». Vid. Gaceta del Congreso No. 547 de 2009. 
Sobre la ponencia para segundo debate ${ }^{90}$ solo diremos que constituye una reiteración de los argumentos vertidos en este y en anteriores PAL. Allí el ponente - ex novo- sostiene, que la impunidad se resuelve aumentando penas, y que las penas existentes son insuficientes, ${ }^{91}$ situación que, desde su punto de vista, genera reincidencia en este tipo de conductas -tampoco aporta dato alguno que ratifique las aludidas reincidencias- por lo que considera necesaria «una nueva construcción filosófica de país y una nueva mirada de la sociedad con relación a los niños». ${ }^{92}$

Como muestra adicional del desinterés jurídico del legislador y de su interés electoral y politiquero ${ }^{93}$ por sacar adelante el acto legislativo propuesto, y con independencia de si tal modificación constituye o no un retroceso desde el punto de vista del derecho penal, podemos citar apartes del debate surtido en la plenaria de la Cámara de Representantes, ${ }^{94}$ en la que pueden observarse los reclamos expuestos por algunos miembros de esa colegiatura, acerca del inicial desinterés del Gobierno en sacar adelante esta iniciativa, y el repentino interés por que la misma salga avante: ${ }^{95}$

(...) Señor ministro, quisiera preguntarle a su señoría ¿Cuál fue la razón que motivó al Gobierno Nacional para cambiar de posición? El señor presidente de la República en una entrevista reciente le dijo al país de manera clara y contunden que era suficiente los 60 años que contemplaba el Código

90 Vid. Gaceta del Congreso No. 243 de 2009.

91 De contravención menor cataloga la autora del proyecto las penas existentes. Vale la pena registrar sus manifestaciones: «A lo que aspiramos es que las máximas penas de hoy sean las mínimas de mañana, o sea que no siga siendo una contravención menor por ejemplo un episodio de abuso, que es como se suele calificar sofisticadamente una violencia sexual, así no haya penetración»; a continuación les recuerda a los parlamentarios que los ojos de las víctimas están puestos sobre ellos y enseguida les pide «dos minutos del video y luego que nos regalen un minuto para que el país los observe a ustedes haciendo ese minuto de silencion. Vid. Gaceta del Congreso No. 542 de 2009.

92 El texto definitivo, aprobado en segundo debate, reposa en la Gaceta 313 de 2009 (Cámara).

93 Conviene registrar la definición de la palabra politiquear que ofrece la RAE:

1. intr. Intervenir o brujulear en política.

2. intr. Tratar de política con superficialidad o ligereza.

3. intr. Am. Hacer política de intrigas y bajezas.

Vid. https://dle.rae.es/?id=Ta6qf4s (consultado el 28/02/2019).

94 Acta de plenaria No. 174. Vid. Gaceta del Congreso No. 542 de 2009.

95 Llama la atención que la misma titular del proyecto reconozca que éste solo contiene un efecto simbólico sin resultado disuasorio: «Nadie ha dicho que eso va a solucionar el problema, eso sería poco menos que absurdo, pero es el símbolo de la sociedad, es el comienzo del fin, es una nueva forma de cómo la sociedad colombiana debe dirigirse hacia sus niños (...)». Esta afirmación contraría la misma exposición de motivos, donde se indica que «lo se busca con este Referendo Constitucional [es] contar con una estrategia preventiva, ya que su implementación y desarrollo normativo deberán impedir que los delitos que se busca castigar se continúen cometiendo». Vid. Gaceta del Congreso No. 80 de 2009. 
134 Prisión perpetua en Colombia. Análisis de las Iniciativas Legislativas para su autorización, y de los argumentos "racionales» para su incorporación en el ordenamiento colombiano

Emiro Cáceres-González

Penal para este tipo de conductas (...) , y de un momento a otro cambia de posición. Queda entonces ante la opinión pública que al Gobierno Nacional le pasa lo del camaleón, que cambia cada vez que le interesa, que les llame la atención poder impulsar el famoso referendo de la reelección presidencial. Todo el país sabe señor ministro, lo que se esconde detrás del impulso que el Gobierno Nacional desde este Congreso quiere con el referendo del agua y con este referendo que estamos estudiando en la tarde de hoy. (...) Debo señalar que no tengo absolutamente ninguna objeción con respecto a la importancia de este referendo, por supuesto que soy consciente del drama que se está viviendo en todos los hogares de Colombia con una situación tan lamentable como la que hoy está ocurriendo en este país, pero lo que no está bien es que se pretenda aprovechar estos dos referendos para que arrastre el famoso referendo reeleccionista, que es lo que finalmente motivó al Gobierno Nacional para que se embarcara en el impulso de estos dos. ${ }^{96}$ (...) Sé que este Gobierno y el señor ministro solo quieren que los referendos lleguen ese día junto al estudio de la reelección, para que la gente engañada acuda a las urnas (...) no entiendo el gesto bondadoso del Gobierno de venir a apoyar este referendo, ahora cuando sabe que lo tiene como gancho para que ese día la gente se haga presente a las urnas y vote por la reelección (...) no quiero que a través de este acto de politiquería se quiera engañar al pueblo colombiano, y que convencido que va a votar por algo bueno, termine aumentando el número de electores presentes en las urnas y así se perpetúe el doctor Uribe en el poder. ${ }^{97}$

(...) Creo que hay un truco, y el truco es arriar a la gente al tema de la reelección presidencial. Aquí no se puede seguir engañando. Le respondo al doctor Santos y al doctor Navas. El cambio de la actitud del Gobierno frente al tema del agua, frente al tema de la cadena perpetua se da porque quiere juntar los tres referendos para arriar a la gente, para conseguir los siete millones doscientos mil votos en el tema central del Gobierno, y el tema central del Gobierno y de la Bancada de Gobierno es la reelección presidencial; en eso no hay ninguna equivocación. ${ }^{98}$

96 Intervención del Representante a la Cámara, Guillermo Antonio Santos Marín. Vid. Gaceta de Congreso No. 542 de 2009.

97 Intervención del Representante a la Cámara, Germán Navas Talero. Ibídem.

98 Intervención del Representante a la Cámara, Germán Enrique Reyes Forero. Ibíd. 
La extensión del documento y la finalidad perseguida con el mismo, no nos permite ahondar en el análisis de la veracidad o falta de crédito de estos señalamientos; sin embargo, sí ponen en evidencia un aparente interés oculto, 0 al menos un segundo interés, por parte del Gobierno de la época por impulsar este proyecto de acto legislativo, el que al parecer apoyó repentinamente, no porque tuviera un interés legítimo en su contenido, sino porque eventualmente podría beneficiarlo; con lo que se hace palmaria no solo -en palabras de Paredes Castañón-, ${ }^{99}$ la hipocresía del legislador, de los partidos y de las bancadas interesadas en apoyar la aprobación del referendo reeleccionista, sino también el falso interés y la hipocresía del Gobierno de turno.

Siguiendo adelante con los postulados retóricos utilizados para reforzar la -únicapretensión de criminalización a perpetuidad, encontramos en la ponencia para tercer debate, ${ }^{100}$ afirmaciones relativas al trato excepcional que tendría la pena de prisión perpetua, la que, al parecer, para el ponente de la iniciativa, generaría automáticamente un efecto adicional, referido a una aparente y automática cobertura con la que se garantizarían los derechos de los menores, así se infiere cuando afirma que este tipo de pena «simbolizará que nuestros niños, niñas, y adolescentes tendrán un tratamiento preferencial no solo en los enunciados Constitucionales, sino en las decisiones políticas, sociales y jurídicas frente a sus derechos, los cuales tendremos el imperativo de cumplirn. ${ }^{101}$

El texto anterior alude, a la creación de un aparente sistema con el que se protegerán y harán prevalecer los derechos de los menores desde el punto de vista político, social y jurídico; sin embargo, una vez se continúa con la lectura del texto, no se hace visible sustento dialéctico que soporte su propuesta, ${ }^{102}$ por lo que puede pensarse que para el ponente, la creación de la pena perpetua, será insumo suficiente para conseguir ese resultado, notándose así su interés inocuizador, pues seguidamente, alude a que la tensión de derechos entre la proporcionalidad de la pena y la prevalencia

99 Señala el profesor de la Universidad de Oviedo que «(...) ni siquiera el más desinteresado y sereno de los líderes políticos puede ni debe prescindir por completo de las implicaciones emocionales, simbólicas y electorales de aquellas decisiones políticas que adopta. De manera que sí, es cierto: En algún sentido (limitado, cuando menos), existe siempre, cuando se propone un cambio legislativo, cierta hipocresía en las alegaciones de que se hace por (pura) racionalidad, por el "interés general"». Vid: Paredes Castañón, José Manuel, "Racionalidad instrumental del legislador y estereotipos sociales sobre la delincuencia: Modelos de argumentación punitivista", en Revista Brasileira de Ciências Criminais, vol. 147, septiembre de 2018, pp.405-431.

100 Vid. Gaceta del Congreso No. 406 de 2009.

101 Cit.

102 Se decide convenientemente aludir a un discurso populista donde el legislador se muestra pro-defensor del interés superior del menor, invocando una protección jurídica, política y social en su favor, pero sin informar de qué manera la imposición de una pena a perpetuidad generará semejante nivel de cobertura. 
136 Prisión perpetua en Colombia. Análisis de las Iniciativas Legislativas para su autorización, y de los argumentos "racionales» para su incorporación en el ordenamiento colombiano

EMIro Cáceres-González

del interés superior de los menores, es simplemente aparente o ficticia; ${ }^{103}$ pasando por alto, otros principios como el de intervención mínima, ultima ratio, resocialización, entre otros, los que, al parecer no entran en tensión, viabilizando con ello, la cosificación del individuo, mediante la decisión consciente de encerrar y botar las llaves. ${ }^{104 / 105}$

Las discusiones legislativas llevadas en tercer debate, a partir de la mencionada exposición de motivos, ${ }^{106}$ revelan de una parte, el interés electoral que envuelve -0 puede envolver a futuro- la iniciativa, y el eventual costo político que puede conllevar el oponerse a su contenido; de otra parte, demuestran el poco respeto y el nulo interés del legislador por la evolución y los desarrollos dogmáticos conseguidos a partir del pensamiento ilustrado. De hecho, pareciera que, para el legislador, la sujeción a una serie de principios de contenido constitucional, en vez de ser necesarios y convenientes, son una molesta talanquera que hay que buscar derribar, o al menos esquivar, así ello traiga consigo, la aplicación de un derecho de corte prebeccariano.

Las intervenciones vertidas por algunos de los Senadores que participaron del debate dan cuenta del ánimo perverso de inocuización pretendido en contra de este tipo de delincuencia, la cual, sin desconocer que es absolutamente aberrante, no por ello habilita a prodigar un trato estigmatizador automático, al considerarles como seres eternamente detestables e irresocializables como premisa legal y constitucional. Las frases incorporadas en las discusiones legislativas dan cuenta de un discurso cargado de odio por parte de quien hace las leyes, de la creación de un bullyng legislativo en contra de este tipo de delincuencia, de la reiteración de la relación ciudadano/enemigo, y del abandono de los más elementales criterios dogmáticos. ${ }^{107}$

Ahora bien, como lo hemos dicho, el costo político que acarrea ir en contra de la posición dominante, y en pro de la defensa de los principios liberales, se ve reflejado en la intervención de uno de los senadores participantes, quien pone en evidencia que, ir en contra de esta iniciativa eventualmente se paga en las urnas:

103 Ibídem.

104 En la ponencia se lee que «la prisión perpetua no debe ser el fin, debe ser ante todo el medio para comenzar a luchar contra la violencia demencial que afecta a nuestros menores de edad». Ibíd.

105 Interesante artículo del portal Dejusticia puede ser consultado en https://www.dejusticia.org/ encerrar-y-botar-la-Ilave-el-todo-vale-en-defensa-de-la-seguridad-ciudadana/ (Consultado el 15 de mayo de 2019)

106 Vid. Gaceta del Congreso No. 660 de 2009, comisión primera constitucional, acta No. 44.

107 Referencias tales como «no es justo que aquí nosotros por una defensa de carácter dogmático tranquemos la oportunidad Constitucional», y «que no solamente sea prisión perpetua sino trabajo perpetuo, que no vayan a pensar los violadores que se van a ir para la cárcel para que el Estado los sostenga durante el resto de su vida, si no que sean sometidos a trabajos», son una muestra del punto al que nos venimos refiriendo. Vid. Gaceta del Congreso No. 660 de 2009. 
(...) Uno no puede venir a pronunciar un discurso aquí, pensando en si se gana los votos o si pierde los votos de los familiares de las víctimas de estos delitos. Yo seguramente los voy a perder, porque muchos no van a entender mi posición, pero doctora Gilma quiero decirle que se trata de un tema de principios y que siendo tema de principios es preferible perder votos que transigir los principios (...), este es el tema más antiliberal que pueda haber, nada tan anti garantista, nada tan antiliberal como la pena de muerte 0 la prisión perpetua, eso es patrimonio de los monjes de la inquisición, eso es patrimonio de las visiones, más oscurantistas y arcaicas del tratamiento del delincuente y de la pena. Pero eso de liberal doctora, no tiene absolutamente nada, es todo lo contrario (...) creemos en un derecho liberal, homo centrista y garantista, el centro del Derecho Penal tiene que ser el hombre, y el Derecho Penal no es para optar por la vía fácil de la muerte o de la prisión perpetua, sino por la vía muy difícil de tratar de recuperar al hombre que delinque, de tratar de reeducar al joven que delinque y de tratar de resocializar al hombre que delinque y esa vía es indudablemente mucho más difícil que la que recordaba ayer el Senador Juan Carlos Vélez, que opera en Irak o en Irán o en la China o en la India, o en Corea del Norte (...) ¿De qué va a servir la prisión perpetua? Sin ocuparnos del tema de la familia, sin ocuparnos del tema de los menores en serio. ${ }^{108}$

En los extractos precedentes puede leerse entre líneas, que los argumentos que más se echan de menos por parte de quienes se mostraron en contra de la utilización de la figura de la prisión perpetua en Colombia son, la falta de criterios técnicos y estudios que justifiquen su necesidad, el uso populista de la pena perpetua para con ella mantener un estatus político y electoral, y la evitación de una auscultación de políticas públicas que proteja a los menores, debido -quizás- a que la misma puede originar mayores demoras y costos.

Sobre estos requisitos puede observarse con mayor claridad las palabras del último interviniente, quien reconoce que

(...) en este país ha hecho carrera la práctica de recurrir al Derecho Penal disque para buscarle solución a los problemas sociales cuando la respuesta a los mismos debe buscarse en otros ámbitos de la actividad pública (...); yo acompañaría este proyecto si estuviera precedido de un estudio criminológico de carácter serio y si ese estudio criminológico nos llevara a la conclusión que la imposición de la cadena perpetua sería la solución 
138 Prisión perpetua en Colombia. Análisis de las Iniciativas Legislativas para su autorización, y de los argumentos "racionales» para su incorporación en el ordenamiento colombiano

EMIro Cáceres-González

para que en Colombia jamás se vuelva abusar sexualmente de un niño. Pero ocurre que estos proyectos son producto de la improvisación, son producto de la coyuntura, son producto de la conmoción social que en un momento dado se genera por la causación de un delito de carácter sexual contra los menores y de la misma manera en que el proyecto es coyuntural, no tiene una propuesta seria, ni tiene unos fundamentos sociológicos que realmente le dan sustento como una medida adecuada para enfrentar el problema de la violación sexual de los menores (...). Yo sé que a través de este Acto Legislativo se podrá llegar a que muchos violadores se vayan a estar el resto de sus vidas en la cárcel, pero doctora Gilma, como no hemos estudiado las causas, seguirán surgiendo otros violadores y lo ideal para la sociedad, lo realmente perfecto dentro del seno del discurrir social, debe ser evitar que los niños sean vulnerados en sus derechos sexuales y eso no se va a lograr con este proyecto de acto legislativo (...) aquí nos han traído ejemplos, es que fulanito violó a una niña, salió y a los quince, veinte o tres meses cometió otro delito, pues precisamente eso lo que está indicando es que el sistema penitenciario no está funcionando adecuadamente, que el ejecutivo no está cumpliendo con el mandato Constitucional de hacer realidad los fines de las penas, que no se está cumpliendo con la finalidad característica del Estado Social de Derecho, que es la reinserción social (...). ${ }^{109}$

Finalmente, la propuesta de referendo modificatorio del texto constitucional consiguió continuar con su trámite y por lo tanto pasar a ser discutido en cuarto debate, sin un ápice de deliberación acerca de los reparos invocados por los disidentes.

Ahora bien, el texto publicado como ponencia para cuarto debate, ${ }^{110}$ no dista mucho de lo reseñado en párrafos precedentes, pues en éste, el denominador común es el manido recurso punitivo-populista y la visión de la pena como medida aislacionista, retributiva y sin fines resocializables, confirmando así la materialización automática de una estratificación delincuencial por imperio de la constitución, con la que se crea una clasificación entre delincuentes de primera (resocializables) y de segunda categoría (no resocializables). Al final, cierra su concienzuda argumentación trayendo a memoria estadísticas desactualizadas ${ }^{111}$ correspondientes a los años 2005-2006, y -al igual que en el PAL presentado en 2008-, nuevamente evoca el lamentable hecho ocurrido con el menor Luis Santiago, citándolo como un hecho ocurrido recientemente, con lo que

109 Intervención del Senador Jesús Ignacio García Valencia. Vid. Gaceta del Congreso No. 660 de 2009.

110 Vid. Gaceta del Congreso No. 467 de 2009 (Senado).

111 Utiliza las allegadas para la vigencia 2005-2006, y presentadas en el PAL 023 de 2007 (Cámara). 
se ratifica nuestra mención a la desidia legisladora, ${ }^{112}$ la que entre sus ligerezas, se atreve a sostener que, del 100\% de los delitos sexuales, el $82 \%$ de los delincuentes son reincidentes, ${ }^{113}$ guardándose para sí la fuente -si es que tuvo- de donde extrajo su cálculo. Por su parte, otra interviniente afirma que esta medida legislativa

(...) va a generar algo muy positivo, niños felices, una sociedad agradable, productiva y eso es lo que queremos (...)», ${ }^{114}$ por lo que es preciso «apoyar una sanción muy severa contra esta clase de malignos y de cerebros pervertidos que no le hacen nada bien a la sociedad y que nunca serán rehabilitados, esas personas nunca se vuelven ciudadanos de bien, siempre van a estar haciéndole daño a todo el que pueden hacerle daño. ${ }^{115}$

Lo lamentable de este panorama, es que el legislador, en vez de procurar mejores alternativas de defensa y prevención de este tipo de conductas, prefiere -quizás por ser más rápido, más barato, y electoralmente más conveniente- huir hacia el derecho penal como mecanismo de intervención, aun siendo consciente de que con este instrumento no se conseguirá ninguna modificación sustancial importante en la realidad social que se plantea como disfuncional.

De hecho, como prueba del interés meramente simbólico que pretenden reflejar en la sociedad, en los medios de comunicación y en los grupos de presión, tres senadores que participaron en el debate legislativo reconocen directa o indirectamente que, a pesar de la falta de estudios serios que demuestren la necesidad de intervención penal, o de la contradicción entre principios dogmáticos y voluntad del pueblo, y específicamente de los grupos de presión, ${ }^{116}$ lo mejor es continuar con su aprobación ya que el coste electoral puede llegar a ser muy alto:

(...) yo he tomado la decisión de votar afirmativamente esta iniciativa, porque en medio de tanta desazón de tanta desesperación, lo urgente es un mensaje, una advertencia, un llamado, un modo con la infancia en

112 Nuevamente señala ese hecho como un suceso reciente (esta semana), cuando el mismo tuvo lugar en septiembre del 2007. Vid. Gaceta del Congreso No. 467 de 2009 (Senado).

113 En el acta de plenaria se lee literalmente: "(...) hay que observar que en estos delitos sexuales, en el ciento por ciento delitos sexuales, el $82 \%$ de incidencia a la reincidencia del delito, 0 sea los violadores vuelven a violar, los violadores vuelven a maltratar». (sic). Cit.

114 Intervención de la Senadora Claudia Rodríguez de Castellanos. Ibídem.

115 Intervención del Senador Jairo de Jesús Tapias Ospina. Ibíd.

116 La intervención de los grupos de presión y de víctimas en el debate legislativo, genera un efecto correlativo: El desinterés por escuchar a los grupos expertos para racionalizar el debate, centrándose especialmente en la satisfacción de la carga emocional que exigen estos grupos. Este es el llamado protagonismo de la plebe. Vid. Díez Ripolles, José Luís, La racionalidad..., Op. cit., pp. 36-41. 
140 Prisión perpetua en Colombia. Análisis de las Iniciativas Legislativas para su autorización, y de los argumentos "racionales» para su incorporación en el ordenamiento colombiano

EMIro Cáceres-González

Colombia es deplorable (sic), si me atuviera al análisis más tranquilo, pues seguramente debería votar negativamente (...). Pero insisto es tal la dimensión de angustia que hay que echar mano del recurso que nos dé esa posibilidad de confianza. ${ }^{117}$

(...) si más adelante, por parte del Estado colombiano se les brinda educación, pues serán menos los que tengan precisamente la implementación de la cadena perpetua, porque ya habrán superado sus traumas psicológicos. Pero mientras nosotros no estemos aquí preparados, para poder nosotros orientar esas personas, pues nosotros tenemos que tomar unas medidas preventivas y esas medidas, es la cadena perpetua para los abusadores sexuales y los maltratadores ${ }^{118}$

(...) voy a votar positivamente el referendo, quiero decirlo de entrada, el referendo de la cadena perpetua, pero también quiero decir que este es un ejemplo en el que las sociedades imponen sus criterios sociales, políticos y culturales por encima de los criterios jurídicos. Y para el país jurídico, lo mínimo que nos merece, es dejar una constancia que signifique, para abogados, para magistrados, para catedráticos, la certeza que sabemos que las condiciones culturales y sociales y políticas impulsan este referendo, pero que, en materia estrictamente jurídica, es un retroceso desde mi perspectiva. Nos estamos devolviendo con este referendo, determinando que los avances en materia de penología, en materia del sentido de la pena y la posibilidad de la resocialización, son avances que dejamos de lado, para optar por el camino de la pena como exclusivo castigo. Lo hacemos por razones culturales, por razones políticas, por razones sociales, pero está claro, que, en términos de estricta academia jurídica, este referendo de cadena perpetua seguramente merecerá amplios debates (...). ${ }^{119}$

Finalmente, el proyecto de convocatoria a referendo consigue ser Ley de la República; ${ }^{120}$ sin embargo, al tratarse de una proposición dirigida a modificar la constitución, y requerir por lo tanto del control previo de constitucionalidad, la

117 Intervención del Senador Jesús Enrique Piñacué Achicué. Vid. Gaceta del Congreso No. 737 de 2009.

118 Intervención de la Senadora Nancy Denise Castillo García. Vid. Gaceta del Congreso No. 835 y 861 de 2009 (Actas de plenaria Senado-texto conciliado y texto definitivo Cámara).

119 Intervención del Senador Roy Leonardo Barreras Montealegre. Ibídem.

120 Ley 1327 de 2009, Por medio de [la] cual se convoca a un referendo constitucional y se somete a consideración del pueblo un proyecto de reforma constitucional. 
Corte Constitucional decide declararlo no ajustado al ordenamiento superior, ${ }^{121}$ pero solamente por vicios de procedimiento. ${ }^{122}$

Después de este intento, las aguas reformadoras dirigidas a variar el contenido del texto constitucional, para incluir la posibilidad de la pena de prisión perpetua en Colombia, se mantuvieron calmas hasta el año 2015, cuando la Cámara de Representantes, radica los PAL $204^{123}$ y 029 de 2015 224 ; ambas iniciativas archivadas por vencimiento de términos, y cuya particularidad es, su identidad de contenido pese a provenir de representantes de partidos políticos diferentes, así como la reiteración expositiva hecha en anteriores propuestas legislativas; tal es el caso de la afirmación hecha en la EM donde se lee que lo pretendido es «(...) la supresión de la prohibición de la pena de prisión perpetua, dotando con ello al legislador de una nueva herramienta dentro del abanico de posibilidades que tiene para la elaboración de la política criminal (...)»,125 adicionando como sustento que el aumento punitivo se hace necesario debido a que

muchos de estos delincuentes ya habían estado condenados a prisión, pagando unos pocos años de prisión intramural, y posteriormente dejados en libertad sin lograr una efectiva resocialización, lo que permitió posteriormente la comisión de gran cantidad de delitos [por lo que], los representantes del pueblo necesariamente debemos cumplir con el clamor de la población en general que demanda penas más severas para los delitos más graves. ${ }^{126}$

Con relación a este último párrafo, infortunadamente el legislador, no ofrece el insumo que resguarda su dicho, ni explica de qué forma se plantea encajar de forma

121 Corte Constitucional, sentencia C-397 de 2010, Magistrado Ponente, Juan Carlos Henao Pérez.

122 Consideramos que el manejo que debe darse en casos puntuales por este Tribunal debería ser más amplio a la mera revisión formal del trámite legislativo. Somos conscientes que el control previo está establecido así en la constitución. No obstante, dicho control previo podría extenderse a revisar aspectos de fondo con los que se pueda comprometer la integridad del texto supremo. Para una revisión al menos introductoria de esta postura, y, refiriéndonos a otras latitudes, puede consultarse, Cáceres González, EMiro, "(I)racionalidad legislativa en la concepción de la Prisión Permanente Revisable en España", en Revista Brasileira de Ciências Criminais, vol. 148, octubre de 2018, pp.18-54.

123 Proyecto de Acto Legislativo 204 de 2015 - Cámara, Por medio del cual se modifica el artículo 34 de la constitución política, suprimiendo la prohibición de la pena de prisión perpetua. Vid. Gaceta del Congreso No. 63 de 2015.

124 Proyecto de Acto Legislativo 029 de 2015 (Cámara), Por medio del cual se modifica el artículo 34 de la constitución política, suprimiendo la prohibición de la pena de prisión perpetua, Vid. Gaceta del Congreso No. 552 de 2015.

125 El mismo párrafo se registra entre otros, en los PAL 204 de 2015 (Gaceta 63 de 2015), 211 de 2016 (Gaceta 1133 de 2016) y más adelante, en el 066 de 2018 (Gaceta 667 de 2018),

126 Cit. 
142 Prisión perpetua en Colombia. Análisis de las Iniciativas Legislativas para su autorización, y de los argumentos "racionales» para su incorporación en el ordenamiento colombiano

Emiro Cáceres-González

correcta su decisión de abandono del mandato resocializador, ni la justificación del traslado al delincuente, de la demostración de haberse resocializado para acceder a la posibilidad de conseguir un horizonte posible de libertad. Complementariamente, en esta oportunidad, el PAL, deja abierta la posibilidad de que sea el legislador quien a posteriori determine, en qué casos sería aplicable la pena irredimible sobre la base de la gravedad del delito, ${ }^{127}$ estableciendo así un riesgoso numerus apertus en los que sería posible la eventual imposición de esta modalidad de sanción, siendo suficiente -por el momento, y para dar trámite a la iniciativa- el que se consiga la modificación constitucional, lo cual, evidentemente, desborda la esfera inicialmente planteada en anteriores proyectos de acto legislativo, en los que se indicaba que este tipo de pena, sería aplicable de manera excepcional y solamente para los casos descritos en sus propuestas de reforma constitucional modificatorios.

Como aspecto novedoso, en comparación con los anteriores proyectos de acto legislativo, vemos que en esta ocasión se incorpora la palabra revisable a la iniciativa, y con apoyo en esta acepción, el legislador llega a la conclusión de que con ello se respetan las garantías penales y constitucionales. No obstante, ni siquiera se molesta en indicar cuál sería el periodo mínimo de privación efectiva de la libertad, ni tampoco la forma y requisitos en que sería procedente el análisis para conceder o negar la misma. ${ }^{128}$

127 El texto propuesto en ambos PAL propone que el texto constitucional quede de la siguiente manera: Artículo 34. Se prohíben las penas de destierro y confiscación.

No obstante, por sentencia judicial, se declarará extinguido el dominio sobre los bienes adquiridos mediante enriquecimiento ilícito, en perjuicio del Tesoro Público o con grave deterioro de la moral social.

De manera excepcional, se podrá imponer pena de prisión perpetua en los eventos en los que la gravedad del delito lo amerite. En todo caso, la pena será revisable en los términos y condiciones que establezca la ley.

128 Se indica en la exposición de motivos que [... ] a diferencia de anteriores iniciativas similares tramitadas ante el Congreso, la presente propuesta de supresión de la prohibición de la prisión perpetua en nuestra Constitución Políitica es respetuosa de las garantías penales, de la siguiente manera:

- Frente al principio de proporcionalidad: En este evento no se está imponiendo una sanción objetiva por determinada conducta, ya que solo se está habilitando la regulación de este tipo de sanción de manera excepcional, atendiendo la gravedad del delito y siempre con revisión de la medida en el término que señale el legislador.

- Frente a la función resocializadora de la pena: Al establecer que la medida tendrá que ser revisada en el término que señale el legislador, se está garantizando la función resocializadora de la pena, ya que esa revisión garantizará que en el caso de que se haya logrado la resocialización del individuo de manera cabal, el mismo pueda ingresar nuevamente a la sociedad rehabilitado plenamente. Este aspecto se replica de lo contenido en el artículo 77 del Estatuto de Roma, anteriormente enunciado.

- Frente a la dignidad humana: Como se puede observar la pena de prisión perpetua es respetuosa de la Declaración Universal de Derechos Humanos, así como de la Convención Americana sobre Derechos Humanos, y se encuentra prevista como sanción por parte de la Corte Penal Internacional. Igualmente, la misma se encuentra prevista por gran cantidad de Estados a nivel internacional, por lo que no se estima que esta medida sea violatoria del principio de la dignidad humana. 
Del PAL 211 de $2016^{129}$ no hay mucho por añadir, ya que la exposición de motivos es reproducción íntegra de las propuestas presentadas en 2015; el único aporte personal -ya que la normativa propuesta también es la misma- es la actualización de las estadísticas, las cuales indica, corresponden a información ofrecida por la Fiscalía General de la Nación, con la que concluye «que los delitos contra la libertad e integridad sexual contra menores de edad entre los años 2009 y 2015 casi que se quintuplicaron [... ]». ${ }^{130}$

A pesar de la estadística añadida, ello no impide sostener que, las mismas no guardan plena correspondencia con la propuesta de texto formulada, ya que, la modificación ahora radicada sugiere que la aplicación de la prisión permanente revisable atienda al vago criterio de la gravedad del delito, pero los cálculos aportados aluden solamente al bien jurídico de la vida e integridad sexual de los menores de edad, ${ }^{131}$ con lo cual, la información suministrada es insuficiente para justificar la variación constitucional en la forma propuesta pues con ello se permitiría que en la ley de desarrollo se incluya un catálogo de tipos penales sobre los que no se aportó información alguna.

De otro lado, consideramos que la estadística allegada, tampoco es suficiente para justificar el aumento punitivo para el segmento concreto de bienes jurídicos informados, ya que el sustrato obrante no puede leerse en una única dirección, tal como lo hace el autor del proyecto, para quien, la cifra en ascenso de casos activos en poder de la Fiscalía General de la Nación llevan a concluir que este tipo de delincuencia va en aumento, pese a que es posible entender también que ese aumento obedezca a la falta de personal especializado para presentar acusación ante los Jueces de Conocimiento, 0 a un represamiento de casos por falta de medios de prueba o de personal investigador, 0 a cualquier otra causa que genere falta de impulso a las denuncias recibidas por el Ente Acusador, razón por la cual, esta fuente de criterio, debió ser complementada con información que ratificara o desvirtuara tales conclusiones, teniendo en cuenta que la propuesta de prisión a perpetuidad bajo la modalidad revisable, compromete

- Frente a una política criminal coherente: Con el proyecto de acto legislativo, no se está imponiendo de manera automática esta clase de pena perpetua, sino que se reitera, solo se está habilitando al legislador, para que de manera excepcional (no aplicará para todos los casos), haga uso de una herramienta viable dentro del abanico de opciones normativas. Por último, de acuerdo a lo establecido por la honorable Corte Constitucional en Sentencias C-1200 de 2003, C-1040 de 2005, C-970 y 971 de 2004, no se está en presencia de una modificación que tenga tal magnitud o trascendencia, que pueda inferir o degenerar en una posible sustitución de la Constitución, ya que evidentemente, el cambio propuesto frente a la disposición actual, no evidencia una incompatibilidad con los elementos definitorios de la identidad de la Constitución, ni se está reemplazando un elemento definitorio de la misma.

129 Vid. Gaceta del Congreso No. 1133 de 2016.

130 Ibídem.

131 Ibíd. 
144 Prisión perpetua en Colombia. Análisis de las Iniciativas Legislativas para su autorización, y de los argumentos "racionales» para su incorporación en el ordenamiento colombiano

EMiro Cáceres-González

derechos fundamentales que no pueden ser tratados como derechos de segunda mano por parte de un legislador que, hasta el momento no se ha preocupado por la creación de una verdadera política pública que salvaguarde los derechos de los menores, que se preocupe por la prevención del delito y desarrolle una política criminal que identifique las causas por las que se delinque, y procure el fortalecimiento del sistema penal a fin de evitar la congestión judicial, la impunidad, las dilaciones en los procesos penales, la falta de confianza en las instituciones públicas y en general, la consecución de una recta y eficaz labor de administrar justicia.

En el año 2017 los intentos legislativos para impulsar la prisión perpetua en Colombia vinieron tanto del Senado como de la Cámara de Representantes, mediante la presentación del PAL $17^{132 / 133}$ y los PAL $55^{134}$ y $240 .{ }^{135}$ El contenido de estas propuestas, nos permite ratificar que el escaso esfuerzo dialéctico, y el carente sustento empírico llevado por el legislador, hacen parte del orden del día, pues en esta oportunidad el legislador se conforma con transliterar segmentos considerables de los proyectos de acto legislativo números 029, y 204 de 2015 y 211 de 2016.

Es de resaltar que dentro de la justificación del proyecto presentado para primer debate al PAL 17 de $2017^{136}$-también llamada Ley Yuliana Samboni-, ${ }^{137}$ se reconoce la efectividad y la capacidad de respuesta del Ente Investigador y del aparato jurisdiccional para recopilar elementos probatorios, los cuales permitieron identificar y condenar de manera rápida al responsable de los hechos de la ley que lleva el nombre de la víctima a quien se rinde homenaje; sin embargo, tal mención no se hace para destacar la labor realizada por el aparato jurisdiccional e investigativo, sino para cuestionar la pena impuesta, la que para el ponente de la iniciática es insuficiente:

132 Vid. Gaceta del Congreso No. 308 de 2017.

133 Omitimos intencionalmente hacer mención del PAL 12 de 2016, también conocido como Ley Yuliana Samboní, ya que la exposición de motivos de uno y otro proyecto conserva prácticamente intacta su redacción, agregando a la del 2017, el vocablo revisable, el que en 2016 se había omitido, dejándose solo en el título del proyecto, pero no en el articulado propuesto. Vid. Gaceta del Congreso No. 1104 de 2016.

134 Vid. Gaceta del Congreso No. 640 de 2017.

135 Vid. Gaceta del Congreso No. 178 de 2017.

136 Vid. Gaceta del Congreso No. 178 de 2017.

137 Este proyecto de acto legislativo recibió este nombre como consecuencia de un aberrante hecho ocurrido en 2016 sobre la menor mencionada. La víctima fue brutalmente violada y asesinada por un reconocido arquitecto, miembro de una acaudalada familia, y que causó un gran revuelo mediático, así como el reclamo ciudadano en la calle y en redes sociales. Ver https://www.eltiempo.com/ justicia/delitos/historia-del-caso-de-rafael-uribe-noguera-por-muerte-de-yuliana-samboni-72468 (Consultado el 19/02/2019). 
(...) la respuesta a este crimen atroz por parte de las autoridades, policía nacional y fiscalía fue tan oportuna que lograron la captura y aseguramiento del asesino, y luego de no más de seis meses, el confeso violador y asesino ya estaba condenado con la mayor pena a imponer según la circunstancia, 50 años y 10 meses de prisión, condenado con una pena de tal magnitud gracias a ley de feminicidio promulgada un año antes. Sin embargo, a pesar de la cuantiosa condena al mencionado arquitecto la sociedad entera sigue sedienta de justicia, y temerosa por el ejercicio de la justicia en lo que se refiere a la ejecución de las penas, pues el decir de la mayoría es que de nada sirve una elevada condena si al cabo de 2 03 años ya están fuera de la cárcel porque se les sustituye la prisión por la detención en el domicilio, o por rebaja de la pena como resultado del buen comportamiento, estudio y trabajo, y ese es el gran temor que un asesino 0 violador en serie pueda regresar a las calles en poco tiempo, con el riesgo de volver a reincidir en los mismo delitos, porque es clara y demostrada la proclividad que tienen los asesinos y violadores en serie a la comisión de ese tipo de crímenes; siendo entonces ese tipo de circunstancias y realidades las que han llevado a todos los sectores de la sociedad a unirse en un clamor, el de pedir que ese tipo de personas sean castigadas con penas severas como es la prisión perpetua al considerar que esa es la única forma de mantenerlos apartados de la sociedad y así garantizar que no estén al ruedo por las calles (sic) cobrando la vida de menores indefensos y personas vulnerables (...). ${ }^{138}$

En el anterior razonamiento, se deja entrever lo que hemos dicho supra, acerca de la doble estratificación delincuencial, la confirmación del trato ciudadano/enemigo, la cooptación de garantías fundamentales, el abandono del fin resocializador de las penas, y la negación de la posibilidad de obtención de rebajas de pena por estudio y trabajo como un derecho del penado. ${ }^{139}$ Todo ello, sin dejar de lado la mención totalizadora hecha, acerca de que los autores de estas conductas son por regla general, reincidentes y/o asesinos y violadores en serie.

Sobre los tres últimos PAL citados, el Consejo Superior de Política Criminal (CSPC) emitió concepto desfavorable acerca de la procedencia de esta medida punitiva, que al conservar completa coincidencia entre las tres propuestas legislativas, las archivadas y

138 Vid. Gaceta del Congreso No. 178 de 2017.

139 Este último aspecto lo abordaremos brevemente infra. 
146 Prisión perpetua en Colombia. Análisis de las Iniciativas Legislativas para su autorización, y de los argumentos "racionales» para su incorporación en el ordenamiento colombiano

Emiro Cáceres-González

la que se encuentra en curso en la actualidad, debía atenerse a lo dicho en el concepto número 01-2017, ${ }^{140}$ donde se pronunció acerca del PAL 211 de 2016. ${ }^{141}$

Continuando con la cronología de los proyectos presentados para eliminar de la Constitución la prohibición de penas perpetuas, los PAL $223^{142}$ y 066 de $2018^{143}$ no distan mucho de las particularidades y comentarios hechos hasta ahora. Comencemos entonces por el PAL 223 de 2018, donde es notoria, la ya citada desidia legisladora, ya que no actualiza contenidos, ni trae ideas propias, citando prácticamente los textos de los PAL 204, 029 de 2015 y 221 de 2016. Y el informe de ponencia para primer debate ${ }^{144}$ es una fiel reproducción de las consideraciones registradas en el PAL 055 de 2017.

En similar sentido, el PAL 066 de 2018, no se aparta de la reiteración argumentativa utilizada a lo largo de las legislaturas anteriores, siendo sus modificaciones, las relativas a la fijación de un periodo de 30 años de privación efectiva de la libertad, luego del cual

un comité de expertos dictaminará si el condenado ha podido resocializarse integralmente y no ser un peligro para la sociedad. Si ese comité considera que el condenado se ha rehabilitado en su conducta podrá el juez de ejecución de penas otorgar la libertad condicionada al condenado. Dichos asuntos jurídico - procesales penales deberán ser reglamentados por una norma de rango legal posterior. ${ }^{145}$

Con relación al conocimiento que tiene el mismo legislador, acerca del número de iniciativas que se han presentado para eliminar la prohibición de la pena de prisión perpetua, encontramos que su desconocimiento es patente, ya que, dentro de la EM, refiere solamente a cinco proposiciones, ${ }^{146}$ cuando el recuento que hemos efectuado,

140 Vid. http://www.camara.gov.co/camara/visor?doc=/sites/default/files/2017-09/055\%20-\%2017\%20 C\%20Concepto\%20CSPC.pdf Los conceptos número 01-2017 y 11-2017 pueden ser consultados en la dirección http://www.politicacriminal.gov.co/Instancias/Consejo-Superior-de-Pol\%C3\%ADtica-Criminal/ Conceptos_CSPC/Conceptos-2017 (consultados el 19/02/2019).

141 Al concepto emitido por el CSPC nos referiremos infra.

142 Vid. Gaceta del Congreso No. 134 de 2018.

143 Vid. Gaceta del Congreso No. 667 de 2018.

144 Vid. Gaceta del Congreso No. 210 de 2018.

145 Exposición de motivos, Proyecto de Acto Legislativo 066 de 2018 - Cámara, Por medio del cual se modifica el artículo 34 de la Constitución Política, suprimiendo la prohibición de la pena de prisión perpetua y estableciendo la prisión perpetua revisable - En memoria de Gilma Jiménez. Vid. Gaceta del Congreso No. 667 de 2018.

146 Las palabras del legislador son las siguientes: «en cinco (5) ocasiones presentó el proyecto modificatorio de la Constitución para posibilitar la prisión perpetua. A saber, los Proyectos de Acto Legislativo números 204 de 2015 Cámara; 029 de 2015 Cámara; 055 de 2017 Cámara; 240 de 2017 Cámara; 055 de 2017 Cámara (sic) y 223 de 2018 Cámara fueron archivados por los miembros de la Comisión Primera de la 
demuestra que supera los dieciséis. ${ }^{147}$ Por otro lado, se observa en la exposición de motivos de este PAL que los tipos penales propuestos para la aplicación de la pena perpetua revisable, corresponden a los delitos de homicidio doloso, feminicidio, secuestro y acceso carnal violento cometidos contra menores de 14 años o contra menores de 18 años con discapacidad física y/o mental; empero, los datos estadísticos ofrecidos solamente se refieren a la comisión de delitos de contenido sexual en contra de menores, siendo además la misma información aportada en el año 2016 -la que contiene datos del año 2015 y de años anteriores-, y que se relaciona con el volumen de casos activos en la Fiscalía General de la Nación. En el resto del documento, los argumentos aportados se asemejan a las razones reseñadas en los PAL 204 y 029 de 2015, de los que ya nos hemos ocupado, incluidos, los aspectos sobre la supuesta no vulneración al principio de proporcionalidad, el olvido de la función resocializadora, y el encontrarse acorde con una política criminal coherente y respetuosa de los derechos humanos. ${ }^{148}$

Para empezar con la legislatura 2019, encontramos que el PAL 352, ofrece un articulado similar al presentado en 2018, al incluir la revisabilidad de la pena, pasados 30 años, para los delitos de homicidio bajo la modalidad dolosa, secuestro, tortura, acceso carnal y actos sexuales abusivos con menores de 14 años.

La novedad que debe reconocerse a esta iniciativa es la actualización de la información aportada, la cual extrae del informe forensis 2017, ${ }^{149}$ elaborado por el Instituto Nacional de Medicina Legal y Ciencias Forenses; sin embargo, llama la atención, de una parte, la transcripción literal que hace el autor de la iniciativa, de apartes reseñados en dicho documento, sin que cite su fuente, los cuales son acomodados a conveniencia como elaboraciones propias, y de otra, el uso a su acomodo, de párrafos de ese informe, los cuales descontextualiza, omitiendo incluso apartes allí registrados. Sin embargo, consideramos que, no es su transcripción literal y la abstención de citar la fuente, lo más delicado del proyecto, sino que se descontextualice su contenido, al cercenar y omitir las conclusiones del informe.

Cámara de Representantes del cuatrienio 2014- 2018 sin siquiera ser considerados en primer debate, pues debido a las solicitudes de conceptos tardíos y dilatorios al Consejo de Política Criminal los debates de estos importantes proyectos no pudieron llevarse a cabo con la severidad ni en los tiempos requeridos que estas reformas constitucionales requieren». Ibídem.

147 Incluyendo los PAL presentados en 2019, los cuales, si bien no podrían contarse para esa legislatura, tampoco relacionan la totalidad de los proyectos de acto legislativo presentados hasta ahora.

148 Vid. Gaceta del Congreso No. 1133 de 2016.

149 Disponibleen:http://www.medicinalegal.gov.co/documents/20143/262076/Forensis+2017+Interactivo. pdf/0a09fedb-f5e8-11f8-71ed-2d3b475e9b82 (Consultado el 23/05/2019). 
148 Prisión perpetua en Colombia. Análisis de las Iniciativas Legislativas para su autorización, y de los argumentos "racionales» para su incorporación en el ordenamiento colombiano

EMIro Cáceres-González

Con relación a la descontextualización, lo primero que debemos decir, es que, si bien, el informe aporta una cifra sobre el aumento de casos de violencia sexual en el año 2017, tal cálculo lo hace de manera global sobre un universo en el que se incluyen mayores y menores de edad, y aunque, si bien, la cifra es preocupante, allí se describe un contexto diferente al ofrecido por el autor de la iniciativa legislativa, quien, en su exposición de motivos da la impresión de que dicho informe, hace referencia solamente a los casos de violencia sexual sobre menores.

Por otra parte, con relación al cercenamiento de información, vemos como el pre legislador utiliza este documento para justificar la imposición de la prisión permanente revisable, pasando por alto algunas de las conclusiones a las que llega el Instituto de Medicina Legal en su informe cuando afirma:

La violencia sexual, fenómeno multidimensional en el que confluyen aspectos sociales, culturales, políticos y legales, debe ser abordada como una problemática de salud pública en Colombia. No solamente la legislación debe buscar el castigo a los abusadores, sino impactar en la protección de las posibles víctimas desde el hogar, rompiendo los paradigmas patriarcales y restituyendo de manera efectiva los derechos humanos cuando se avizoren presuntas señales de violencia.

No obstante, las reformas al Código Penal colombiano, en el que se endurecen las penas contra quienes cometan delitos contra la libertad, integridad y formación sexuales y contra quien inflija acceso carnal abusivo con menor de catorce años (12), las cifras alusivas a tales faltas no descienden. Al contrario, el año 2017 demuestra que van aumentando, por lo que el trabajo que se debe realizar no solo debe sustentarse en el acceso a la justicia, sino en la redefinición de protección en el hogar y en el acercamiento de los canales institucionales de atención y denuncia a toda la población. ${ }^{150}$

Finalmente, este PAL fue retirado por el autor, por tránsito de legislatura, advirtiendo al momento de su retiro, su intención de presentarlo nuevamente e invitando a los demás partidos a que se unieran a esta iniciativa.

Iniciado el segundo semestre de 2019, se presentaron los PAL 001 y 047, los cuales fueron acumulados y en la actualidad, se encuentran pendientes de segundo debate. Previo a ello, en primer debate, se presentaron ponencias positivas y negativas. Para el caso de las primeras, es criticable la manera como el legislador pretende dar respuesta al monto de la pena sugerida en la iniciativa: compara los delitos a los que se les podría imponer la prisión permanente revisable, con delitos que regulan bienes 
jurídicos de menor categoría, como los delitos contra el patrimonio económico, los cuales, previamente, el mismo legislador ha venido aumentando de forma desenfrenada para dar respuesta a las presiones de ciertos grupos, para llegar con ello a la conclusión, de que las penas a imponer son proporcionales a la infracción cometida, añadiendo a su discurso, que ello demuestra que no es una medida utilitarista, ni populista, y mucho menos que instrumentalice a un sujeto, ni que vulnere su dignidad como ser humano:

Si se examinan los tipos penales relacionados con delitos violentos de orden sexual en contra de los niños, niñas y adolescentes, se evidencia que tienen penas comparativamente menos graves que otros delitos que afectan bienes jurídicos, y que incluso son menos importantes que la libertad, la integridad y la formación sexual de los menores (...). En efecto, un hurto agravado (artículo 240 C. P.) y calificado (artículo 241 C. P.), cuando la cosa hurtada supera 100 salarios mínimos legales mensuales vigentes (artículo 267 C. P.), tiene una pena máxima de 36 años y 8 meses, es decir, una pena considerablemente mayor al acceso carnal violento y a otros delitos antes mencionados y casi igual que los delitos sexuales contra menores en el marco del conflicto armado. Otro ejemplo de esta desproporción es el delito de tráfico, fabricación o porte de estupefacientes (artículo 376 C. P. Inciso 10) tiene una pena máxima de 30 años, esto es superior a varias de las conductas mencionadas. La misma situación sucede con el terrorismo agravado (artículo 344 C. P.)

(...) La conclusión a la que se puede arribar en este aspecto, es que las penas de los delitos sexuales que se cometen contra menores no son proporcionales a la gravedad del hecho, de ahí que resulte necesario no solo un aumento de pena, sino la posibilidad de imponer excepcionalmente la cadena perpetua para así garantizar una retribución justa y la no reiteración de la conducta por parte del agresor. ${ }^{151}$

Ahora bien-independientemente de si se comparte o no la manera como el legislador acumula la pena para ejemplificar estos tipos penales-, debe indicarse que el insumo utilizado para llegar a esta conclusión, es tomado de las tablas que reposan en la obra La proporcionalidad de las penas en la legislación penal colombiana, ${ }^{152}$ donde los autores del texto critican el desbalance y la falta de juicio del legislador, al momento de aumentar las penas de un determinado tipo penal, al punto que, en sus conclusiones esbozan que «en la situación actual de la legislación penal colombiana y su relación con la política criminal

151 Vid. Gaceta del Congreso No. 752 de 2019.

152 El cual, en esta oportunidad, sí cita el autor de la iniciativa. 
150 Prisión perpetua en Colombia. Análisis de las Iniciativas Legislativas para su autorización, y de los argumentos "racionales» para su incorporación en el ordenamiento colombiano

Emiro Cáceres-González

existen desajustes e inconsistencias que merecen la atención (...) toda norma penal que se proponga expedir debe fundamentarse en razones adecuadas y evidencia empírica, de forma tal que se controlen los excesos fundamentados en el populismo punitivo (...) en muchas ocasiones no es posible evidenciar, durante la discusión legislativa, argumentos que de manera explícita sustenten la necesidad de aumentar cuantitativamente las penas, especialmente que demuestren porqué el margen punitivo vigente no resulta sufciente para responder a los fenómenos criminales involucrados. De este modo, tal como ya lo ha señalado el Consejo Superior de Política Criminal, "en los casos de aumentos de penas posteriores a la criminalización inicial, la argumentación del legislador debe estar dirigida a demostrar la necesidad, proporcionalidad y razonabilidad de la adición en la restricción de la libertad personal de los ciudadanos; debatir y argumentar, en últimas, por qué no sirve la fjación actual y por qué ha de ser aumentada, de tal modo que en el Derecho penal de un Estado democrático no haya márgenes de castigo carentes de justifcación"». ${ }^{153}$

Estas cuestiones, permiten evidenciar la necesidad de un nuevo giro del proceso legislativo, el que, por el momento, se ha caracterizado por un evidente desinterés, y por no tomarse en serio un tema de tal repercusión, que no sólo pone en juego la libertad de un individuo, sino que también pone sobre la mesa, la necesidad de una verdadera política pública de protección de los menores. Las propuestas legislativas de pena a perpetuidad han sido archivadas - hasta ahora- en todas las oportunidades que han sido presentadas, bien por vencimiento de términos, ora por tránsito de legislatura -actualmente, solo se encuentra pendiente, el resultado del PAL 001 de 2019-. No obstante, ello no impide a los autores, a los ponentes y en general, a sus equipos de trabajo, a, siquiera actualizar la información que dentro de su labor ofrecen, a procurar un sustento que al menos permita analizar si procede o no esa medida, a reducir la demagogia, el oportunismo político y el populismo punitivo, y a procurar por una política criminal racional, basada en la evidencia, a fin de identificar las necesidades reales de intervención del ejercicio del ius puniendi del Estado y sus contornos.

\section{La imperiosa necesidad de incorporar criterios de racionalidad al proceso legislativo en materia penal}

Las situaciones presentadas hasta ahora dan cuenta de la débil justificación ofrecida por el legislador, para hacer desaparecer del ordenamiento constitucional la prohibición de penas perpetuas -ahora bajo el eufemismo de prisión permanente revisable-, la que no es otra cosa, que una involución en el sistema de penas colombiano.

153 Cita Triana, Ricardo Antonio, González Amado, Iván, La proporcionalidad de las penas en la legislación penal colombiana, Bogotá, Ibáñez, 2017, pp. 241-246. 
El presente trabajo, no pretende, sin más, cuestionar de forma automática, la imposición de penas a perpetuidad -las que si bien, no compartimos-, sino demostrar que hasta el momento, el legislador, simplemente ha hecho prevalecer su criterio políico -o politiquero-, sobre el criterio técnico, sin importarle mínimamente, que sus decisiones legislativas se fundamenten en bases que racional y técnicamente respalden la necesidad de intervención penal. Hasta el momento, no existen de intentos legislativos dirigidos a proteger al menor mediante la consolidación de una verdadera política pública - de la cual la política criminal hace parte en una pequeña porción- de prevención y protección de este sector poblacional, por lo que, hasta ahora sólo se han ofrecido placebos legislativos, con los que se pretende mostrar a la sociedad, la falsa idea de estar haciendo algo.

Ahora bien, sin ánimo de justificar el obrar del legislador, si nos ponemos en sus zapatos, notaremos que sus decisiones e intervenciones legislativas no son tan racionales como se ha creído en el tiempo; ${ }^{154}$ pero debemos ser concientes que, dentro del desempeño de su función, se ve envuelto en un movimiento circular que, en materia penal es bastante recurrente, y que se origina entre él, grupos de presión y medios de comunicación. ${ }^{155}$ Allí el legislador es puesto bajo la -quizás conveniente- tesitura de decidir entre apoyar el aumento punitivo, y argüir la tesis populista y barata de estar atendiendo al clamor social -aunque no sea del todo cierto-, ${ }^{156} 0$-eventualmente-, asumir el costo político que le podría acarrear no atender tal pedimento.

Bajo este prisma la pregunta a resolver es si esas dos opciones son las únicas posibles, y desde nuestro punto de vista, consideramos que la respuesta debe ser negativa.

En este sentido, para solucionar esta aparente tensión, debemos reiterar la necesidad de que el proceso legislativo, salga del tradicional método de argumentación simplista llevado hasta ahora, y hacer que evolucione a un proceso en el que, luego

154 De ahí el mito del legislador racional. Vid. Por todos, Marcilla Cóndoba, Gema, Racionalidad Legislativa, Crisis de la ley y nueva ciencia de la legislación. Madrid, Centro de Estudios Políticos y Constitucionales, 2005, p. 113-127.

155 Similar panorama nos ofrece Pozuelo Pérez, Laura, La política criminal mediática, Madrid, Marcial Pons, 2013, pp. 88-96, quien divide este escenario en cuatro fases: 1) Introducción de la alerta de aumento de la delincuencia por el poder político. 2). Maximización del asunto por el medio de comunicación. 3). Aumento de preocupación ciudadana y, 4). Reforma legislativa de corte represivo. Sin embargo, esta autora -al igual que otros autores- pasa por alto la encrucijada a la que se somete al legislador al tener que escoger entre prestar oídos a los grupos de presión, o asumir posibles consecuencias en las urnas, si no apoya la iniciativa.

156 Decimos que así no sea del todo cierto, ya que hay que distinguir entre la construcción irreflexiva del delito creada a partir de las demandas de la llamada opinión pública, y la creada mediante juicios públicos informados, la cual surge a partir de contextos sociales de deliberación. Vid. Green, David, "Public opinion versus public judgment about crime", en British Journal of Criminology, No. 46, 2006, pp. 131-154. 
del debate decisional la articulado que se adopte no sea simplemente el impuesto por la regla de mayorías, sino más bien, sea fruto de un debate de argumentos donde se ventilen, no solo cuestiones retóricas, dirigidas a cumplir el rito consagrado para el íter legislativo, sino también, que tenga en cuenta argumentos morales, empíricos, dogmáticos, criminológicos, y de todas aquellas áreas transdisciplinarias, ${ }^{157}$ que sean necesarias para tomar una decisión verdaderamente racional y justificada, e incorporando criterios de necesidad y proporcionalidad.

Ahora bien, es cierto que, ni la Constitución, ni la Ley Orgánica del Reglamento del Congreso (LORC), señalan concretamente la necesidad del aporte de documentos específicos a los PL y PAL, ni ofrece pinceladas sobre el contenido que debe tener la parte dispositiva, o la exposición de motivos; sin embargo, consideramos que, ello per se no puede entenderse como una habilitación para que los facultados constitucionalmente para ello -especialmente en materias político criminales-, lo sigan haciendo como lo hacen; y mucho menos, que se pueda argüir que el debate legislativo en la práctica, es una mera formalidad cuyo fin es dar la apariencia legitimadora de haber escuchado otros puntos de vista, pero que en realidad constituye un momento intrascendente donde las etapas del debate se trasforman en un sinsentido jurídico y en un sinsentido técnico, ${ }^{158}$ debido a que, para el legislador, lo importante es, apelar a la superficialidad que ofrece la politiquería; pues incluso con ello, se soslaya el verdadero sentido de la política y la democracia, mediante el uso de una política peyorativa. ${ }^{159}$

Por lo anterior, consideramos que el legislador debe sujetarse siquiera a dos mandatos actualmente vigentes, con los que se pretende racionalizar su producto: Uno de carácter interno, establecido en la LORC, y otro de carácter externo, correspondiente a las órdenes impartidas por la Corte Constitucional, y que pasan a desarrollarse:

157 Redondo Illescas, Santiago, Garrido Genovés, Vicente. Principios de Criminología. Valencia: Tirant lo Blanch, 2013, p. 126 «las políticas criminales funcionan de modo acientífico, es decir, con total ignorancia de los conocimientos disponibles, o peor aún, contracientífico, o sea, haciendo justo lo contrario de lo que el conocimiento criminológico [y de otras ciencias] prescribe».

158 Sinsentido desde el punto de vista de creer innecesario el aporte y análisis documentalmente fundado.

159 Reiteramos que, para una mejor comprensión acerca de lo que queremos anunciar, conviene registrar el alcance de la definición de la palabra politiquear que nos ofrece la RAE:

1. intr. Intervenir o brujulear en política.

2. intr. Tratar de política con superficialidad o ligereza.

3. intr. Am. Hacer política de intrigas y bajezas. 


\subsection{Desconocimiento del mandato interno: La Ley Orgánica del Reglamento del Congreso (LORC)}

De conformidad con el artículo 145 de la LORC, para presentar un PAL o un PL no es necesaria la presentación de documentos que justifiquen su trámite, bastando el cumplimiento de un requisito meramente formal, correspondiente al señalamiento de un título, un encabezamiento, una parte dispositiva y una exposición de motivos; sin embargo, consideramos que, si pretendemos materializar un debate más racional en materia penal, este rito resulta insuficiente para la aceptación a trámite de un proyecto de esta naturaleza, al encontrarnos frente al más extremo de los mecanismos de intervención del Estado mediante el ejercicio del ius puniendi. Recordemos que la obligación del legislador, es la sujeción a la constitución y a la ley, las que consagran el respeto de garantías y derechos supremos, por lo que, evidentemente, estos requisitos pueden verse transgredidos al omitirse los soportes que justifican la necesidad de intervención legislativa penal; situación que hace imperioso que, desde la misma presentación de la iniciativa, y luego, dentro de los debates, se haga uso de criterios de racionalidad y de herramientas empíricas de apoyo, puesto que, a menor sustento demostrativo, menor legitimidad tendrá la futura normativa penal, y en consecuencia, mayores sospechas de inconstitucionalidad. ${ }^{160}$

Ahora bien, como ya lo hemos anotado, ha hecho carrera al interior de la célula legislativa $-y$ la doctrina al parecer lo ha aceptado-, que se crea suficiente el cumplimiento de las condiciones del artículo 145 de la LORC, para dar trámite a un PL o PAL; sin embargo, si hacemos una lectura más completa del reglamento vigente, notaremos que esta situación fue corregida por la Ley 1147 de 2007,161 la cual adiciona la LORC, creando la Comisión Especial de Modernización del Congreso.

Dentro de los artículos que componen esta ley, resulta de interés transcribir los objetivos que el legislador le ha asignado a la Unidad Coordinadora de Asistencia Técnica Legislativa (UATL), en procura de una mejora del proceso legislativo, con lo que

160 Para Habermas, Jürgen, Facticidad y validez. Sobre el Estado democrático de derecho en términos de teoría del discurso (Trad. Jiménez Redondo, Manuel), Madrid, Trotta, 2005, pp. 363-366, la legitimidad de la norma estará circunscrita a que en el procedimiento legislativo se cumplan ciertos requisitos que la racionalicen.

161 Al consultarse esta ley en la página de la Secretaría General del Senado, se encuentra en las notas que: «en criterio del Editor, teniendo en cuenta que la "Comisión Especial de Modernización del Congreso" es una "comisión especial» según lo dispuesto por el artículo 2 de la Ley 1147 de 2007, publicada en el Diario Oficial No. 46.685 de 10 de julio de 2007, debe entenderse adicionada a la Sección 3a. - "Comisiones Especiales», del Capítulo IV - "De las Comisiones del Congreso»»; es decir la Ley 5 de 1992 (LORC). Vid. http://www.secretariasenado.gov.co/index.php/ley-5-de-1992 (Consultado el 07/03/2019). 
154 Prisión perpetua en Colombia. Análisis de las Iniciativas Legislativas para su autorización, y de los argumentos "racionales» para su incorporación en el ordenamiento colombiano

EMIro Cáceres-González

se ratifica que la aplicación del artículo 145 de la LORC es insuficiente para dar trámite a un PAL o PL:

ARTíCULO 6o. Unidad Coordinadora de Asistencia Técnica Legislativa, UATL. Son objetivos de la UATL brindar servicios de apoyo jurídico y asesoría técnica a las Comisiones Constitucionales y Bancadas del Congreso. Son funciones de esta Unidad: 1. Procurar la alta calidad de los proyectos de ley, de Acto Legislativo y de la discusión legislativa por medio de investigaciones técnicas y objetivas. 2. Apoyar por medio de asesorías técnicas y objetivas la calidad de los proyectos de ley, de Acto Legislativo y de la discusión legislativa. 3. Fortalecer las iniciativas legislativas presentadas en el Congreso con la participación oportuna de la sociedad. 4. Establecer un vínculo constante con la comunidad académica para facilitar el análisis de los temas legislativos, por medio de la suscripción de convenios de cooperación. 5. Adelantar el programa de judicatura y pasantías legislativas para la Unidad con las distintas universidades nacionales y extranjeras. 6 . Las demás que le asigne la Comisión.

Por lo visto, pese a ser una ley del año 2007, en materia penal esta norma ha sido una carta de buenas intenciones que ha pasado desapercibida para el legislador, para la doctrina, e incluso para la Corte Constitucional; por lo tanto, se ha creído, sin efecto vinculante en la toma de decisiones legislativas, por lo que debe exigirse su cumplimiento, a fin de hacer más serio, fundado y técnicamente más legítimo el íter legislativo y así evolucionar en la dirección correcta, mejorando el proceso legiferante al interior del ágora congresional.

\subsection{Desconocimiento del mandato externo: Las órdenes impartidas al legislador por la Corte Constitucional Colombiana}

Con relación a la manera como se viene realizando el proceso legislativo, la Corte Constitucional ha sentado una posición clara, impartiendo órdenes al legislador acerca de la manera como debe cumplir su función. En esa dirección, le ha pedido que, dentro de su libertad de configuración legisladora, atienda a criterios de racionalidad y se sujete a ciertos estándares. Es así que, dentro de las sentencias T-153 de 1998, T-338 de 2013 y T-762 de 2015, ese Tribunal, declaró un estado de cosas inconstitucional (ECI) en las prisiones colombianas y en el sistema penitenciario y carcelario, ${ }^{162}$ por lo

162 De manera general, la declaratoria del ECI en un país democrático, corresponde a la manifestación hecha por su Tribunal Constitucional, al advertir que, al confrontar la efectividad del texto supremo con la realidad que se vive en el país, emerge que dicha efectividad es meramente formal. En este 
que, como consecuencia de tal declaratoria, y con miras a mejorar el tercer proceso de criminalización, le ha hecho una serie de recomendaciones al legislador, a fin de racionalizar la primera etapa de dicho proceso; es decir, el proceso legiferante.

En este sentido la Corte Constitucional, con base en el informe presentado por la Comisión Asesora de Política Criminal en 2012, ${ }^{163}$ determinó que «en Colombia los entes encargados de la formulación y el diseño de la política criminal (Congreso y Gobierno Nacional, entre otros) han adoptado decisiones de forma reactiva y sin fundamentos empíricos sólidos» por lo que

tales decisiones están generalmente basadas en la necesidad de responder con celeridad a fenómenos sociales mediados por la opinión pública y de mostrar resultados contra el crimen, para aumentar la popularidad de un determinado sector político. [Por lo que,] no tienen como principal finalidad impactar los índices de criminalidad y, rara vez, se sostienen en fundamentos sólidos que permitan relacionar la expedición de una norma y la reducción real de un fenómeno criminal. ${ }^{164}$

Bajo este diagnóstico, la Corte considera que, a fin de limitar «el populismo punitivo, es necesario que las instituciones del Estado encargadas de diseñar la política criminal cambien de perspectiva y entiendan que el delito no se puede combatir exclusivamente con el incremento de las penas», ${ }^{165}$ invitando así a los facultados constitucionalmente para presentar, elaborar y tramitar leyes, a que tengan en cuenta que el fin primordial de la política criminal

sentido, para la Corte Constitucional, la situación carcelaria colombiana permite su declaratoria, al concurrir las seis condiciones o factores básicos que la componen: «(i) la vulneración masiva y generalizada de varios derechos constitucionales que afecta a un número significativo de personas: (ii) la prolongada omisión de las autoridades en el cumplimiento de sus obligaciones para garantizar los derechos; (iii) la adopción de prácticas inconstitucionales, como la incorporación de la acción de tutela como parte del procedimiento para garantizar el derecho conculcado; (iv) la no expedición de medidas legislativas, administrativas o presupuestales necesarias para evitar la vulneración de los derechos. (v) la existencia de un problema social cuya solución compromete la intervención de varias entidades, requiere la adopción de un conjunto complejo y coordinado de acciones y exige un nivel de recursos que demanda un esfuerzo presupuestal adicional importante; (vi) si todas las personas afectadas por el mismo problema acudieran a la acción de tutela para obtener la protección de sus derechos, se produciría una mayor congestión judicial."» Vid. Corte Constitucional, Sentencia T-388 de 2013, fundamento jurídico 4.1.5.

163 Vid. Diagnóstico y propuesta de lineamientos de política criminal para el Estado colombiano. Disponible en https://www.minjusticia.gov.co/portals/0/info\%20poli\%20criminal_final23nov.pdf (consultado el 10/03/2019)

164 Corte Constitucional, sentencia T-762 de 2015, F.J., 31.

165 Cit., F.J., 53. 
156 Prisión perpetua en Colombia. Análisis de las Iniciativas Legislativas para su autorización, y de los argumentos "racionales» para su incorporación en el ordenamiento colombiano

EMIro Cáceres-González

actual, es obtener una efectiva resocialización del condenado. ${ }^{166}$ En este sentido, le ordena al Congreso a que: 167

dentro del ámbito de sus competencias y respetando su libertad de configuración normativa, dé aplicación al estándar constitucional mínimo de una política criminal respetuosa de los derechos humanos», y a que, "dé aplicación a lo dispuesto en los artículos $3^{\circ}$, numeral $6^{\circ}$, y 18 del Decreto 2055 de 2014, en el sentido de contar con el concepto previo del Comité Técnico Científico del Consejo Superior de Política Criminal, para iniciar el trámite de proyectos de ley o actos legislativos que incidan en la política criminal y en el funcionamiento del Sistema de Justicia Penal» al igual que "promuevan la creación, implementación y/o ejecución de un sistema amplio de penas y medidas de aseguramiento alternativas a la privación de la libertad.

A pesar de estas menciones, si confrontamos los intentos legislativos que nos han ocupado, con las órdenes emitidas por este Tribunal, podremos concluir que dichas iniciativas, constituyen no solo una vulneración al mandato consignado en el reglamento del Congreso (LORC), sino también una vulneración al mandato emitido por la intérprete constitucional, al no ajustarse a un estándar constitucional mínimo de una política criminal respetuosa de los derechos humanos, ni promover, crear o implementar un sistema amplio de penas y medidas de aseguramiento alternativas a la privación de la libertad. ${ }^{168}$ Por el contrario, se continúa con la implantación de un gobierno securitario, en el que las garantías y derechos de los procesados son residuales, y donde los reclamos derechos de las víctimas y los grupos de presión prevalecen, gobernado así, a través del delito, ${ }^{169}$ mediante el uso frecuente de la fórmula ciudadano/enemigo.

\subsubsection{El (des)interés del legislador al concepto previo del Comité Técnico Científico del Consejo Superior de Política Criminal}

Como lo vimos en el anterior apartado, la Corte Constitucional le ha ordenado al legislador que, previo al inicio del trámite de un PL o PAL que envuelva cuestiones de política criminal, cuente «con el concepto previo del Comité Técnico Científico del

166 Cit., F.J., 57.

167 Cit. Artículo vigésimo segundo de la parte resolutiva de esa decisión judicial.

168 Sobre el concepto del CSPC nos ocuparemos a continuación.

169 Simon, Jonathan, Gobernar a través del delito, Gedisa, 2011, Barcelona. Para este autor «el eje de la nueva racionalidad en el dictado de leyes es la víctima del delito» 
Consejo Superior de Política Criminal». El fin perseguido con esta directriz debe ser, que sus investigaciones sirvan como punto de partida al momento de contemplar una modificación a la política criminal del Estado. Sin embargo, la Corte no señala de forma concreta, que lo tenga en cuenta y atienda a su contenido, sino simplemente que al momento de la presentación del PL o PAL cuente con este concepto.

Esta parece ser la interpretación dada por el parlamento colombiano a esta orden, puesto que, para el caso que nos concierne, encontramos que si bien, a partir del PAL 211 de 2016, se ha cumplido con el aporte al dossier legislativo, del análisis efectuado por el CSPC, ${ }^{170}$ también encontramos éste no es tenido en cuenta para los futuros debates 0 ponencias, convirtiéndose con ello, en una aportación intrascendente para el legislador, con fines meramente instrumentales, dirigidos a dar la apariencia de atendido el llamado de ese tribunal. Lo dicho se confirma revisando los PAL presentados desde 2016, los cuales, hasta el segundo semestre de 2019, conservaron identidad argumentativa reiterarando su concepto desfavorable, remitiéndose para ello al análisis hecho al PAL presentado en 2016, en el que, mediante concepto 01-17171 explicó in extenso las razones por las que consideraba inconveniente la aplicación de dicha medida legislativa.

Sobre el análisis efectuado por el CSPC, podemos decir que brilla por su ausencia pronunciamiento alguno por parte de los legisladores o pre legisladores que han presentado 0 apoyado estas iniciativas, a fin de exponer las razones por las que se apartan de las palabras de ese órgano -0 si al menos conocen el concepto-.

En su remplazo, el creador de la ley sigue presentando iniciativas con reiterado contenido, y sin que hasta este momento se haya interesado por efectuar manifestación alguna, acerca de las valoraciones allí efectuadas pese a que en su oportunidad, se le puso de presente, entre otras cuestiones, que para abordar el debate, se hacía necesario evaluar la gravedad del delito y su proporcionalidad, analizar el fin resocializador de las penas, evitar la incoherencia actual de la política criminal y la necesidad del aporte de evidencia empírica.

La única mención que el legislador, ha hecho al concepto emitido por el CSPC ${ }^{172}$ es el efectuado en la EM del PAL 066 de 2018, ${ }^{173}$ donde se lee con cierto desprecio,

170 Es decir, se ha contado con el concepto del CSPC en los PAL 017, 055, 240 de 2017 y en los PAL 223 y 066 DE 2018.

171 Vid.http://www.politicacriminal.gov.co/Portals/0/Conceptos/ConceptosCSPC/2017/01\%20 CSPC\%20PLA\%20211,\%20PL\%20197,\%20199\%20y\%20200.pdf (Consultado el 11/03/2019)

172 Nos referimos al sector de la rama legislativa que sigue defendiendo sin bases la imposición de las penas perpetuas en Colombia, ya que, como lo anotamos previamente, los dos últimos PAL han sido objeto de presentación de ponencia negativa por un sector de los parlamentarios designados como ponentes, siendo éstos quienes han apelado a su contenido, para criticar la iniciativa legislativa.

173 Vid. Gaceta del Congreso No. 667 de 2018. 
158 Prisión perpetua en Colombia. Análisis de las Iniciativas Legislativas para su autorización, y de los argumentos "racionales» para su incorporación en el ordenamiento colombiano

Emiro Cáceres-González

que sus iniciativas han sido archivadas debido a las solicitudes de conceptos tardíos y dilatorios al Consejo de Política Criminal [lo que generó que] los debates de estos importantes proyectos no pudieron llevarse a cabo con la severidad ni en los tiempos requeridos que estas reformas constitucionales requieren. ${ }^{174}$

Como si lo dicho en anterior oportunidad por ese consejo, hubiera sido atendido y dentro de la iniciativa legislativa se estuvieran ofreciendo nuevas medidas legislativas con las que se diera respuesta a los reparos formulados, no solo por el CSPC, sino también por la Corte Constitucional, e incluso, en cumplimiento de la LORC.

Ahora bien, en 2019 el CSPC conceptuó de manera diferente a la manera como lo venía haciendo con anterioridad, dando luz verde a la iniciativa legislativa, y considerando que la misma no trasgrede el ordenamiento constitucional al incorporar en ella la prisión perpetua revisable. Tal giro argumentativo tuvo lugar a partir de cambio del titular al interior del Ministerio de Justicia, y la renuncia del presidente de la Comsión Asesora de ese Consejo, quien puso en entredicho la independencia académica de la Comisión y el actual papel de ese Ministerio sobre el tema. ${ }^{175}$ Adicionalmente, debe tenerse en cuenta que, el informe que considera ajustada al ordenamiento colombiano la pena de prisión perpetua, fue presentado con posterioridad al entregado por los integrantes de la anterior comisión asesora, encabezada por su anterior presidente, quienes de manera detallada puntualizaron la falta de sustento empírico de la iniciativa. ${ }^{176}$ Resaltamos dentro de ese informe la siguiente acotación:

con el dinero que le cuesta al Estado la manutención por cada cupo penitenciario de un condenado a prisión perpetua ( $\$ 643$ millones de pesos sin incrementos anuales), se podrían financiar casi cuatro carreras universitarias completas (suponiendo que cada carrera -10 semestres- cueste en promedio 170 millones de pesos). En este caso, es irónico que el Estado invierta más recursos en los victimarios que en la rehabilitación, tutela y protección de los menores; 0 en educación, políticas sociales o incrementos de puestos de trabajo, etc. ${ }^{177}$

Esta consideración escarnece el escueto análisis hecho por el legislador, para quien es suficiente afirmar que la sociedad reclama su inocuización como única forma

174 Ibídem.

175 Ver entre otras, https://www.asuntoslegales.com.co/actualidad/renuncio-el-presidente-de-comisionasesora-en-politica-criminal-2882869 (consultado el 20/09/2019).

176 Curiosamente, el informe presentado por quienes conformaban esta comisión, fue subido a la página web del CSPC, y a los pocos minutos fue retirado de allí sin explicación alguna.

177 Pese a que el documento fue retirado de la página web del CSPC, puede consultarse en https:// caracol.com.co/descargables/2019/07/15/35bbaf4e10c83e929c6979e446032629.pdf 
de garantizar sus derechos mínimos a preservar su vida; crear falacias argumentativas es quizás lo único que no merecen los niños, niñas y adolescentes que esperan que se garanticen sus derechos frente a sujetos de especial peligrosidad que atentan y acechan su posibilidad de desarrollar su individualidad y su plan vida de manera libre. ${ }^{178}$

Apreciaciones similares a las del anterior párrafo, son las esbozadas en el concepto 12 de 2019, donde el CSPC, ${ }^{179}$ sostiene que la cadena perpetua puede ser un mecanismo efectivo para proteger a los menores, pero sin explicar las razones por las que así lo considera, confundiendo en su concepto, el desarrollo de una política pública preventiva, con la sanción de la conducta; adicionalmente, utiliza el mismo argumento del legislador, al justificar el aumento punitivo, sobre la comparación de otros bienes jurídicos de menor categoría, los cuales olvida, han sido objeto de permanente aumento por el legislador, en atención a la demanda ciudadana, sin contar con análisis alguno de necesidad ni de proporcionalidad.

En suma, el nuevo concepto, no justifica, ni técnica, ni dogmática, ni empíricamente el cambio legislativo sugerido, por lo que, el contenido de este nuevo concepto, se suma al incumplimiento de las órdenes dadas por la Corte Constitucional, acerca del estandar mínimo de constitucionalidad, por lo que su contenido, adolece de criterios de razonabilidad, y por contera, pone en entredicho el rigor y la legitimidad que debe rodear el proceso legislativo.

\section{Conclusiones}

Desde el año 2007 se vienen presentando varios proyectos de modificación constitucional con el fin de eliminar la prohibición de penas a perpetuidaden Colombia. Se ha pretendido introducir esta figura, para delitos que, por su gravedad, se harían acreedores a tal posibilidad de sanción, bien bajo la modalidad revisable, ora sin posibilidad alguna de revisión.

Hasta ahora, los proyectos presentados no han visto la luz -salvo la ley 1327 de 2009, la cual fue declarada inexequible por la Corte Constitucional por vicios en su procedimiento-, por lo que, cada una de estas iniciativas han sido retiradas 0 archivadas por vencimiento de términos.

El presente estudio, no se dirige a cuestionar, sin más, la imposición de penas a perpetuidad en Colombia; sino ir más allá y revisar los proyectos que se han presentado,

178 Vid. Gaceta del Congreso No. 752 de 2019.

179 Disponible en: http:/www.politicacriminal.gov.co/Portals/0/Conceptos\%20CSPC/ Conceptos2019CSPC/12.\%20CSPC _ \%20PAL\%2001\%20Y\%20PAL\%2047\%20de\%202019\%20 C\%C3\%A1mara-Prisi\%C3\%B3n\%20perpetua.pdf (consultado el 23/09/2019). 
160 Prisión perpetua en Colombia. Análisis de las Iniciativas Legislativas para su autorización, y de los argumentos "racionales» para su incorporación en el ordenamiento colombiano

Emiro Cáceres-González

sus exposiciones de motivos y sus debates. El resultado de ello, es la identificación de los siguientes puntos comunes: 1). La existencia de un debate binario, ciudadano/ enemigo. 2). La intención de contención de ese no ciudadano, por el mayor tiempo posible, al considerarse que no es un ser resocializable. 3). El permanente aumento de la conminación penal, con el fin de venderle a la sociedad una falsa idea de seguridad, ${ }^{180}$ $y, 4)$. La recurrente falta de racionalidad en el debate legislativo, acompañada de un carente sustento empírico que demuestre la real necesidad de intervención penal.

La investigación advierte evidentes muestras de desidia legisladora, ocurridas desde el momento mismo de la presentación de los proyectos, ya que muchas de estas iniciativas, simplemente trascriben proyectos previamente archivados, los cuales se reencauchan sin mayor estudio.

Esto genera un injustificado desconocimiento de la modificación hecha por la Ley 1147 de 2007, que adicionó la Ley Orgánica del Reglamento del Congreso (LORC), y las órdenes impartidas por la Corte Constitucional al declarar el ECl, donde impuso que en materia político criminal, el legislador solicite, y tenga en cuenta el concepto del Consejo Superior de Política Criminal. Por esta razón, es obligación de la academia, de la ciudadanía y de los tribunales, exigir su cumplimiento, pues con ello transitaremos hacia una legislación más coherente y con mayor peso empírico, así como con una mejora en la toma de decisiones legislativas; generando con ello, que las posiciones del legislador salgan del cómodo argumento de la regla de las mayorías, como única fuente generadora de la voluntad ciudadana, complementándose con un debate racional, fundado, documentado y sopesado, donde se tenga en cuenta la voz de las minorías, de la academia y de los grupos expertos -y no expertos-, antes de tomar la decisión legislativa, evitando así, que el íter legislativo se convierta en una mera formalidad con la que se pretende dar legitimidad al discurso populista con el que se vienen justificando las ideas criminalizadoras.

\section{Bibliografía.}

Beccaria, Cessare, De los delitos y de las penas (Traducción y notas de Francisco Tomás y Valiente), Barcelona, Orbis, 1984, pp. 82-83.

Becerra Muñoz, José, La toma de decisiones en política criminal: Bases para un análisis multidisciplinar, Valencia, Tirant Lo Blanch, 2013.

Cáceres GonzÁlez, Emiro, Derecho Penal y Derecho Administrativo Sancionador: Elementos de racionalidad legislativa, Bogotá, Leyer, 2018.

180 Silva Sánchez, Jesús María, La expansión del derecho penal, aspectos de la política criminal en las sociedades posindustriales, Madrid, Edisofer, 2011. 
Cáceres González, Emiro, "(I)racionalidad legislativa en la concepción de la Prisión Permanente Revisable en España", en Revista Brasileira de Ciências Criminais, vol. 148, octubre de 2018, pp.18-54.

Cerezo Domínguez, Ana Isabel, El protagonismo de las víctimas en la elaboración de las leyes penales, Valencia, Tirant Lo Blanch, 2010.

Cita Triana, Ricardo Antonio, González Amado, Iván, La proporcionalidad de las penas en la legislación penal colombiana, Bogotá, Ibáñez, 2017.

Díez Ripollés, José Luis, La racionalidad de las leyes penales, práctica y teoría, Madrid, Trotta, 2013.

GreEN, DAvid, "Public opinion versus public judgment about crime", en British Journal of Criminology, No. 46, 2006.

Habermas, Jürgen, Facticidad y validez. Sobre el Estado democrático de derecho en términos de teoría del discurso (Trad. Jiménez Redondo, Manuel), Madrid, Trotta, 2005.

Jakobs, Günther, Derecho penal del enemigo, Madrid, Cívitas, 2006.

Larrauri, Elena "Populismo punitivo...y como resistirlo", en Revista Jueces para la democracia, No. 55, marzo de 2006.

López Medina, Diego Eduardo, El derecho de los jueces: obligatoriedad del precedente constitucional, análisis de sentencias y líneas jurisprudenciales y teoría del derecho judicial, Bogotá, Legis, 2006.

Marcilla Córdoba, Gema, Racionalidad Legislativa, Crisis de la ley y nueva ciencia de la legislación. Madrid, Centro de Estudios Políticos y Constitucionales, 2005.

Paredes Castañón, José Manuel, "Racionalidad instrumental del legislador y estereotipos sociales sobre la delincuencia: Modelos de argumentación punitivista", en Revista Brasileira de Ciências Criminais, vol. 147, septiembre de 2018, pp.405-431.

Pozuelo Pérez, Laura, La política criminal mediática, Madrid, Marcial Pons, 2013.

Redondo lllescas, Santiago, Garrido Genovés, Vicente. Principios de Criminología. Valencia: Tirant lo Blanch, 2013.

Robert, Julián Stalans, Loretta, Indermaur, David, Hough, Mike, Penal populism and public opinión. Lessons from five countries, Nueva York, Oxford University Press, 2003

Silva Sánchez, Jesús María, La expansión del derecho penal, aspectos de la política criminal en las sociedades posindustriales, Madrid, Edisofer, 2011.

Simon, Jonathan, Gobernar a través del delito, Gedisa, 2011, Barcelona. 
Sozzo, Máxımo, "Populismo punitivo, proyecto normalizador y "Prisión-Depósito" en Argentina, en Sistema penal \& Violencia. Revista electrónica da Facudade de Dereito, Volume 1, Número 1, p. 33-65 - julho - dezembro, 2009.

Sotomayor Acosta, Juan Oberto, "Las recientes reformas penales en Colombia: Un ejemplo de irracionalidad legislativa", en Nuevo Foro Penal, No. 71, 2007, pp. 13-66,

\section{Gacetas del Congreso}

Gaceta del Congreso No. 339 de 2007.

Gaceta del Congreso No. 355 de 2007.

Gaceta del Congreso No. 519 de 2007.

Gaceta del Congreso No. 685 de 2008.

Gaceta del Congreso No. 741 de 2008.

Gaceta del Congreso No. 080 de 2009.

Gaceta del Congreso No. 182 de 2009.

Gaceta del Congreso No. 243 de 2009.

Gaceta del Congreso No. 313 de 2009.

Gaceta del Congreso No. 406 de 2009.

Gaceta del Congreso No. 467 de 2009.

Gaceta del Congreso No. 542 de 2009.

Gaceta del Congreso No. 547 de 2009.

Gaceta del Congreso No. 660 de 2009.

Gaceta del Congreso No. 737 de 2009.

Gaceta del Congreso No. 835 de 2009.

Gaceta del Congreso No. 861 de 2009.

Gaceta del Congreso No. 063 de 2015.

Gaceta del Congreso No. 268 de 2015.

Gaceta del Congreso No. 552 de 2015

Gaceta del Congreso No. 635 de 2015.

Gaceta del Congreso No. 1133 de 2016.

Gaceta del Congreso No. 1104 de 2016.

Gaceta del Congreso No. 178 de 2017.

Gaceta del Congreso No. 308 de 2017. 
Gaceta del Congreso No. 504 de 2017.

Gaceta del Congreso No. 640 de 2017.

Gaceta del Congreso No. 890 de 2017.

Gaceta del Congreso No. 18 de 2018.

Gaceta del Congreso No. 134 de 2018.

Gaceta del Congreso No. 210 de 2018.

Gaceta del Congreso No. 667 de 2018.

Gaceta del Congreso No. 752 de 2018.

Gaceta del Congreso No. 778 de 2018.

Gaceta del Congreso No 760 de 2018.

Gaceta del Congreso No. 974 de 2018.

Gaceta del Congreso No. 975 de 2018.

Gaceta del Congreso No. 173 de 2019.

Gaceta del Congreso No. 321 de 2019.

Gaceta del Congreso No. 326 de 2019.

Gaceta del Congreso No. 614 de 2019.

Gaceta del Congreso No. 664 de 2019.

Gaceta del Congreso No. 669 de 2019.

Gaceta del Congreso No. 744 de 2019.

Gaceta del Congreso No. 752 de 2019.

Gaceta del Congreso No. 1004 de 2019.

Gaceta del Congreso No. 1038 de 2019.

\section{Jurisprudencia}

Corte Suprema de Justicia, Sala Penal, Providencia del 19 de abril de 2002, Rad. 7026.

Corte Suprema de Justicia, Sala Penal, Providencia del 28 de julio de 2004, Rad. 18654.

Corte Constitucional, sentencia C-551 de 2003.

Corte Constitucional, sentencia C-1200 de 2003.

Corte Constitucional, sentencia C-970 de 2004.

Corte Constitucional, sentencia C-971 de 2004.

Corte Constitucional, sentencia C-1040 de 2005.

Corte Constitucional, sentencia C-397 de 2010.

Corte Constitucional, sentencia T-388 de 2013. 
164 Prisión perpetua en Colombia. Análisis de las Iniciativas Legislativas para su autorización, y de los argumentos "racionales» para su incorporación en el ordenamiento colombiano

Emiro Cáceres-González

Corte Constitucional, sentencia C-579 de 2013.

Corte Constitucional, sentencia T-718 de 2015.

Corte Constitucional, sentencia T-762 de 2015.

\section{Otros}

Comisión Asesora de Política Criminal, Informe Final, Diagnóstico y propuesta de lineamientos de política criminal para el Estado colombiano. Disponible en: https://www.minjusticia.gov.co/portals/0/info\%20poli\%20criminal final23nov.pdf

Consejo Superior De Política Criminal, Conceptos CSPC-2017. Disponible en: http://www.politicacriminal.gov.co/Instancias/Consejo-Superior-dePol\%C3\%ADtica-Criminal/Conceptos_CSPC/Conceptos-2017

Consejo Superior De Política Criminal, Estudio al Proyecto de Acto Legislativo No. 001 de 2019 Cámara "Por medio del cual se modifica el artículo 34 de la Constitución Política, suprimiendo la prohibición de la pena de prisión perpetua y estableciendo la prisión perpetua revisable" - En memoria de Gilma Jiménez; Acumulado con el Proyecto de Acto Legislativo 047 de 2019 Cámara "Por medio del cual se modifica el artículo 34 de la Constitución Política, estableciendo la prisión perpetua revisable, y se dictan otras disposiciones" Disponible en: http://www.politicacriminal.gov.co/ Portals/0/Conceptos\%20CSPC/Conceptos2019CSPC/12.\%20CSPC _ \%20PAL\%20 01\%20Y\%20PAL\%2047\%20de\%202019\%20C\%C3\%A1mara-Prisi\%C3\%B3n\%20 perpetua.pdf (consultado el 23/09/2019).

Consejo Superior De Política Criminal, Estudio del Consejo Superior de Política Criminal al Proyecto de Acto Legislativo 240 de 2017 Cámara, por medio del cual se modifica el artículo 34 de la Constitución Política, suprimiendo la prohibición de la pena de prisión perpetua. Disponible en: http://www.camara. gov.co/camara/visor?doc=/sites/default/files/2017-09/055\%20-\%2017\%20 C\%20Concepto\%20CSPC.pdf

Consejo Superior De Política Criminal, Estudio del Consejo Superior de Política Criminal relacionados con cuatro (4) propuestas legislativas de intervención sobre las agresiones sexuales que afectan a los niños, niñas y adolescentes en Colombia. Disponible en: http://www.politicacriminal.gov.co/Portals/0/ Conceptos/ConceptosCSPC/2017/01\%20CSPC\%20PLA\%20211,\%20PL\%20 197,\%20199\%20y\%20200.pdf 
Consideraciones sobre la implementación de la pena de prisión perpetua en Colombia Comisión Asesora en materia de Política Criminal 23 de mayo de 2019. Disponible en:https://caracol.com.co/descargables/2019/07/15/35bbaf4 e10c83e929c6979e446032629.pdf

Diccionario de la lengua española, palabra: Politiquear. Disponible en: https://dle.rae. es/?id=Ta6qf4s

El minuto a minuto de la trágica historia de Luis Santiago. Disponible en: https:// www.elcolombiano.com/historico/co _ cronologia _ secuestro _ del nino _luis_santiago _lcg _ 30092008-GEec_ 15553

Encerrar y botar la llave: el "todo vale" en defensa de la seguridad ciudadana. Disponible en: https://www.dejusticia.org/encerrar-y-botar-la-llave-el-todovale-en-defensa-de-la-seguridad-ciudadana/

Informe Forensis 2017 datos para la vida, Instituto Nacional de Medicina Legal y Ciencias Forenses, Disponible en: http://www.medicinalegal.gov.co/ documents/20143/262076/Forensis+2017+Interactivo.pdf/0a09fedb-f5e811f8-71ed-2d3b475e9b82

Ley 5 de 1992. Disponible en: http://www.secretariasenado.gov.co/index.php/ley5-de-1992

Línea de tiempo: esto ha ocurrido tras el asesinato de Yuliana Samboní. Disponible en: https://www.eltiempo.com/justicia/delitos/historia-del-caso-de-rafaeluribe-noguera-por-muerte-de-yuliana-samboni-72468

Proyecto de Acto Legislativo 163 de 2008 (CÁmara), Por medio de la cual se modifica el artículo 34 de la Constitución Política, cadena perpetua abusadores niños. Disponible en: https://congresovisible.uniandes.edu.co/proyectos-de-ley/ ppor-medio-de-la-cual-se-modifica-el-articulo-34-de-la-constitucion-politicacadena-perpetua-abusadores-ninos/1559/\#tab $=2$

Proyecto de Acto Legislativo 223 de 2008 (CÁmara), Por medio del cual se modifica el artículo 34 de la Constitución Política, suprimiendo la prohibición de la pena de prisión perpetua. [Permite la Cadena perpetua]. Disponible en: https:// congresovisible.uniandes.edu.co/proyectos-de-ley/ppor-medio-del-cual-semodifica-el-articulo-34-de-la-constitucion-politica-suprimiendo-la-prohibicionde-la-pena-de-prision-perpetua-permite-la-cadena-perpetua/9297/\#tab=2

Proyecto de Acto Legislativo 211 de 2016 (Cámara), Por medio del cual se modifica el artículo 34 de la Constitución Política, suprimiendo la prohibición de la pena de prisión perpetua. [Cadena perpetua]. Disponible en: https://congresovisible. 
166 Prisión perpetua en Colombia. Análisis de las Iniciativas Legislativas para su autorización, y de los argumentos "racionales» para su incorporación en el ordenamiento colombiano

EMIro Cáceres-González

uniandes.edu.co/proyectos-de-ley/ppor-medio-del-cual-se-modifica-elarticulo-34-de-la-constitucion-politica-suprimiendo-la-prohibicion-de-la-penade-prision-perpetua-cadena-perpetua/8757/\# tab $=2$

Proyecto de Acto Legislativo 055 de 2017 (Cámara), Por medio del cual se modifica el artículo 34 de la Constitución Política, suprimiendo la prohibición de la pena de prisión perpetua. [Cadena perpetua]. Disponible en: https://congresovisible. uniandes.edu.co/proyectos-de-ley/ppor-medio-del-cual-se-modifica-elarticulo-34-de-la-constitucion-politica-suprimiendo-la-prohibicion-de-la-penade-prision-perpetua-cadena-perpetua/9006/\#tab=2

Proyecto de Acto Legislativo 066 de 2018 (Cámara), Por medio del cual se modifica el artículo 34 de la Constitución Política, suprimiendo la prohibición de la pena de prisión perpetua y estableciendo la prisión perpetua revisable" - En memoria de Gilma Jiménez. [Suprime la prohibición de la pena de prisión perpetua]. Disponible en: https://congresovisible.uniandes.edu.co/proyectos-de-ley/ ppor-medio-del-cual-se-modifica-el-articulo-34-de-la-constitucion-politicasuprimiendo-la-prohibicion-de-la-pena-de-prision-perpetua-y-estableciendola-prision-perpetua-revisable--en-memoria-de-gilma-jimenez-suprime-laprohibicion-de-la-pena-de-prision-perpetua/9494/\#tab=2

Proyecto de Acto Legislativo 352 de 2019 (Cámara), Por medio del cual se modifica el artículo 34 de la Constitución Política, suprimiendo la prohibición de la pena de prisión perpetua y estableciendo la prisión perpetua revisable" -en memoria de Gilma Jiménez. [Cadena perpetua]. Disponible en: https://congresovisible. uniandes.edu.co/proyectos-de-ley/por-medio-del-cual-se/9922/\#tab=2

Renunció Ricardo Posada, presidente de la Comisión Asesora en Política Criminal. Disponible en: https://www.asuntoslegales.com.co/actualidad/renuncio-elpresidente-de-comision-asesora-en-politica-criminal-2882869 